\title{
Die Erneuerung von „Alt-Wien“ im fachlichen und öffentlichen Diskurs
}

Die Notwendigkeit, die Altstadt zu regulieren und „gesund zu machen“, wurde von den Vertretern der Stadterneuerung in den 1930er-Jahren intensiv beworben. Es fehlte ja nicht an schlagkräftigen Argumenten: mangelnde „Hygiene“, vermeintlich notwendige Straßenverbreiterungen für den Verkehr durch die engen Altstadtviertel und die zu erwartende ästhetische und wirtschaftliche Aufwertung. Doch zunehmend war auch Kritik an der Zerstörung von „Alt-Wien“ zu vernehmen. Im Laufe der 1930er-Jahre ist anhand zahlreicher Schreiben an die Zentralstelle für Denkmalschutz und Artikel in Zeitungen und Zeitschriften, von „besorgten Wienern“ ebenso wie von bekannten Persönlichkeiten und Fachleuten aus Architektur und Kunstgeschichte, ein gesteigertes Interesse an der Erhaltung von „Alt-Wien“ nachzuvollziehen. ${ }^{\mathbf{1}}$ Hand in Hand mit der fortschreitenden Stadtregulierung und dem Abbruch zahlreicher, zum Teil denkmalgeschützter Bauten formierte sich gegen Ende der 1930er-Jahre schließlich massiver Widerstand, der sich an einigen in der Öffentlichkeit heftig diskutierten Anlassfällen festmachen lässt.

Im Jänner des Jahres 1938 erging - sozusagen als Höhepunkt dieser Entwicklung unter dem Titel „Rettung des Alten Wien“ eine mit 30.000 Unterschriften unterzeichnete Petition an den Bürgermeister von Wien, den Bundespräsidenten und die Bundesregierung, die sich gegen die rücksichtslose Zerstörung von Altstadtbereichen, vor allem in der Inneren Stadt, aussprach. ${ }^{2}$ Unter den Unterzeichnern finden sich neben bedeutenden Persönlichkeiten des politischen und kulturellen Lebens auch bekannte und einflussreiche Architekten wie Max Fellerer, Josef Hoffmann, Oswald Haerdtl und Clemens Holzmeister. ${ }^{\mathbf{3}}$ Letzterer hatte selbst einen Assanierungsbau auf den ehemaligen Freihausgründen realisiert und war Mitte der 1930er-Jahre, als Präsident der Zentralvereinigung der Architekten, noch als entschiedener Befürworter der Förderung des Bauwesens durch den Assanierungsfonds aufgetreten.

Vergleichbar mit dem Protest gegen die Demolierung von „Alt-Wien“ um die Jahrhundertwende, der die Entstehung der Heimatschutzbewegung befördert hatte, ${ }^{\mathbf{4}}$ sahen sich die Wiener Bevölkerung und die Fachöffentlichkeit in den späten 1930er-Jahren also erneut dazu veranlasst, sich für die Erhaltung der historischen Stadt einzusetzen. Die kritische Wahrnehmung des Verlustes des alten Stadtbildes um 1900 war allerdings nicht nur eine Folgeerscheinung der gesteigerten Bautätigkeit, sondern auch, so Sandor Békési, einer generell im Umbruch befindlichen und durch die wirtschaftlichen und politischen Verhältnisse sensibilisierten Gesellschaft, die einen drohenden Identitätsverlust ortete. ${ }^{\mathbf{5}}$ In den späten 1930er-Jahren traten erneut vergleichbare Voraussetzungen auf. In einer politisch und wirtschaftlich unruhigen Zeit ging der fortschreitende Verlust von „Alt-Wien“ mit einer neuerlich zunehmenden Kritik aus Fachkreisen und aus der Öffentlichkeit einher.

\subsection{Vier Geschichten zum Stadtumbau}

Vor allem Demolierungs- und Neubaupläne in der Innenstadt führten ab 1934 in der Öffentlichkeit zu heftigen Diskussionen. Das große Interesse äußerte sich nicht nur in der ausufernden Berichterstattung der Tageszeitungen, sondern auch in Form privater 
Briefe an die Denkmalschutzbehörde und in einer gesteigerten Anzahl an Fachvorträgen zum Thema. ${ }^{6}$ Der damalige Diskurs reichte von Fragen der Stadtregulierung über Ideen zur Neugestaltung von Straßenzügen bis zum Umgang mit künstlerisch und historisch bedeutsamen Einzelobjekten. Zahlreiche Tageszeitungen berichteten in dieser Zeit mit hoher Frequenz über die lebhaften Debatten. ${ }^{7}$ Die institutionelle Denkmalpflege schaltete sich in den Diskurs ein, die denkmalpflegerischen Interessen mussten sich jedoch mehrmals den Interessen von Stadt- und Verkehrsplanung unterordnen.

\subsubsection{Der Abbruch des Freihauses}

Sehr stark präsent in den Medien war ab 1936 die Neubebauung der Freihausgründe. ${ }^{8}$ Vor allem die Zeitschrift Österreichische Kunst verfolgte mit regem Interesse, wie mit finanzieller Hilfe des Assanierungsfonds „mitten im Zentrum Wiens eine neue Stadt“ emporwuchs. ${ }^{9}$ Das Interesse der Zeitschrift konzentrierte sich verständlicherweise auf die zeitgenössische Architektur der Neubauten und weniger auf denkmalpflegerische Aspekte im Zusammenhang mit dem Abbruch der weitläufigen Wohnanlage aus dem 18. Jahrhundert.

Die Neubebauung der Freihausgründe stellt die umfassendste Bauleistung mithilfe des Assanierungsfonds in Wien dar. Binnen weniger Jahre entstanden hier in einer städtebaulichen Gesamtplanung beiderseits der Verlängerung der Operngasse mehrere Assanierungsbauten (Abb. 68). Die Planung für den Abriss des Freihauses setzte bereits vor dem Ersten Weltkrieg ein (Abb. 69). Nachdem die Union-Baugesellschaft die Anlage 1913 erworben hatte, wurden jedoch aufgrund der schwierigen wirtschaftlichen Verhältnisse bis zum Jahr 1936 lediglich drei Gebäude an der Mühlgasse niedergelegt. ${ }^{10}$

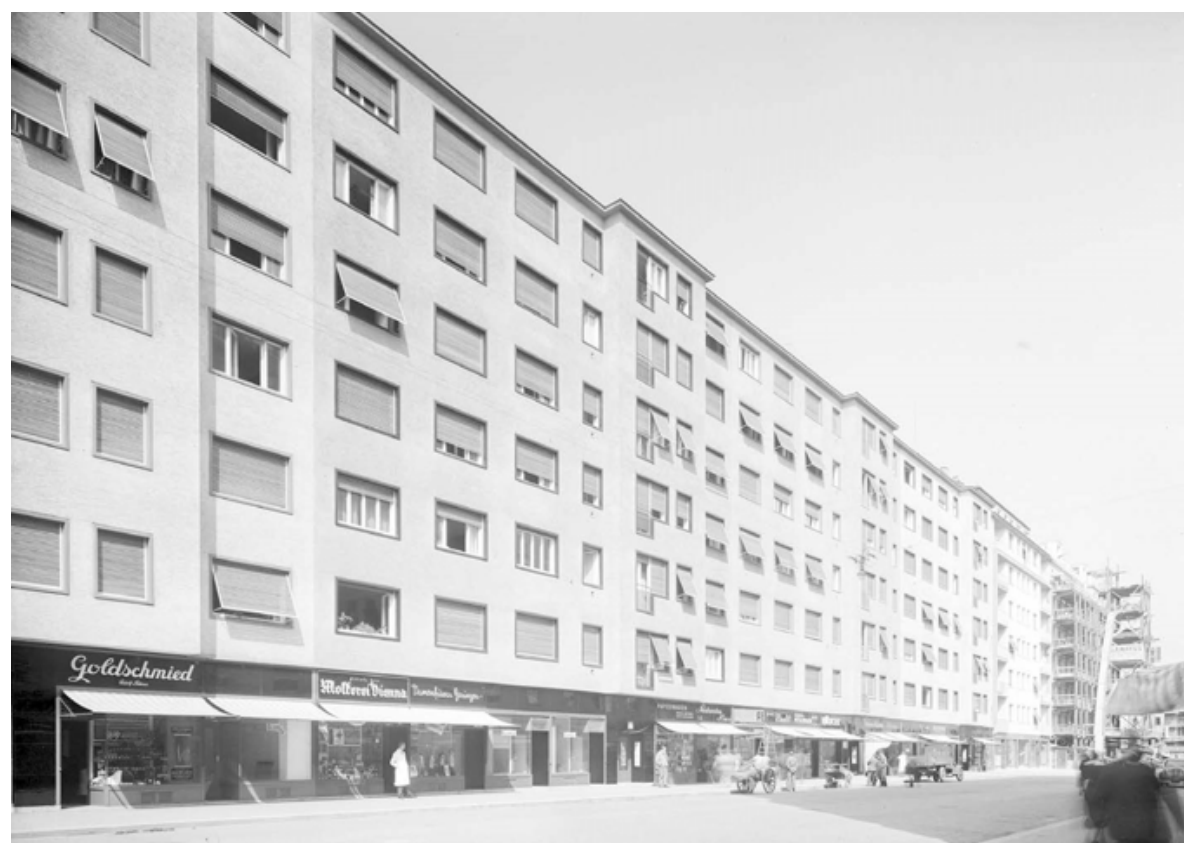

Abb. 68 Fronten der fertiggestellten bzw. in Bau befindlichen Neubauten auf dem Gelände des Freihauses, Operngasse 30-34, 1937 


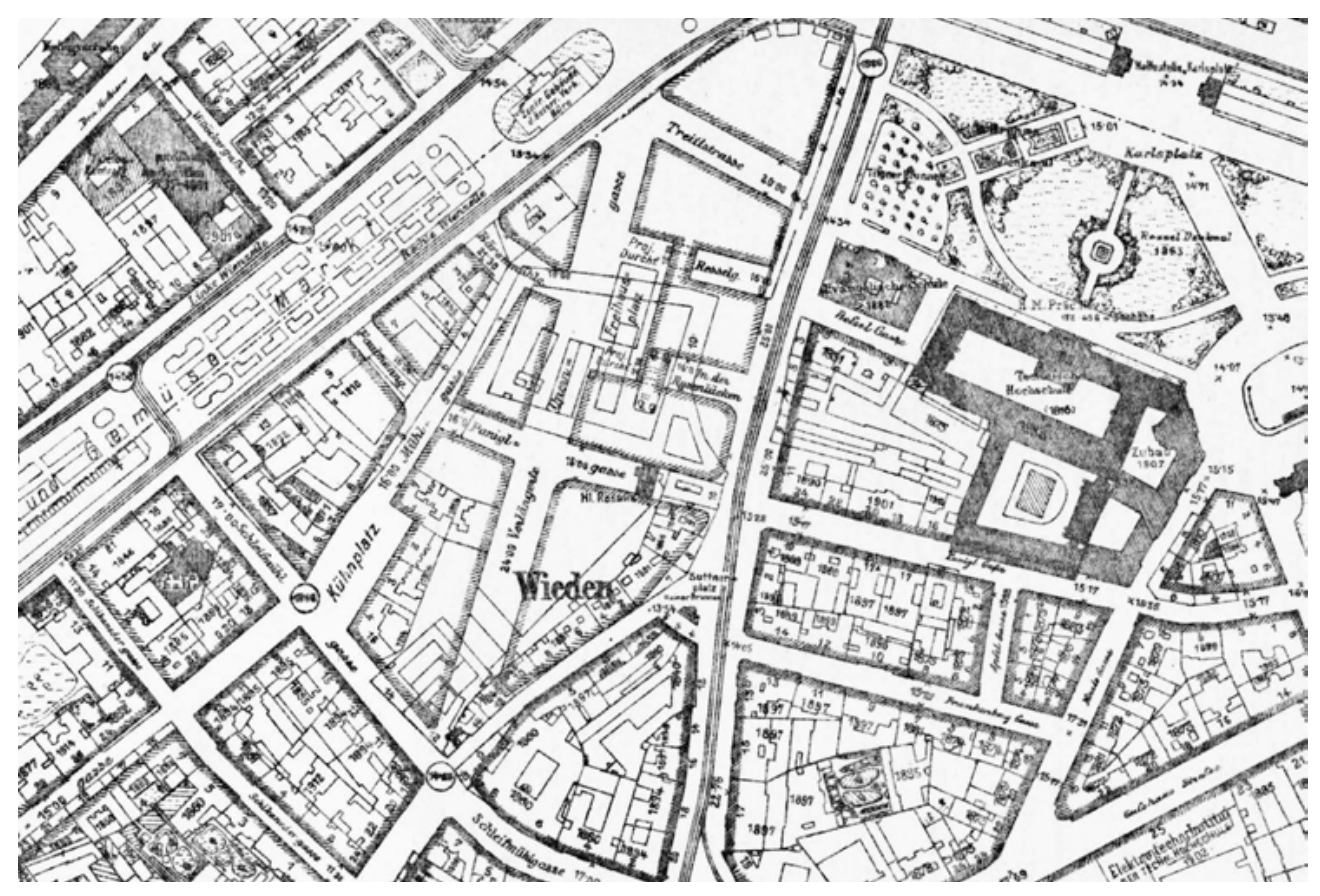

Abb. 69 Generalstadtplan Wien, Ausschnitt mit der damals projektierten Bebauungsstruktur der Freihausgründe, 1923

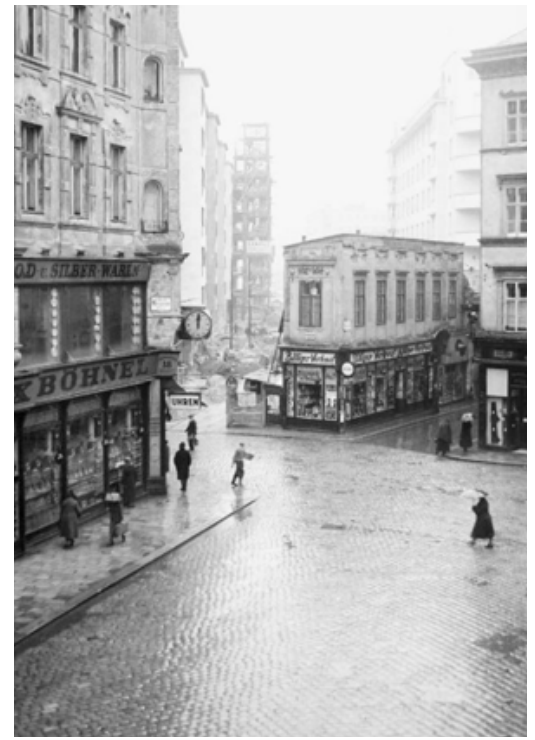

Abb.70 Stockwerkaufnahme auf die Kreuzung Schleifmühlgasse und Operngasse, im Hintergrund die neu angelegte Operngasse, Ausschnitt, um 1935

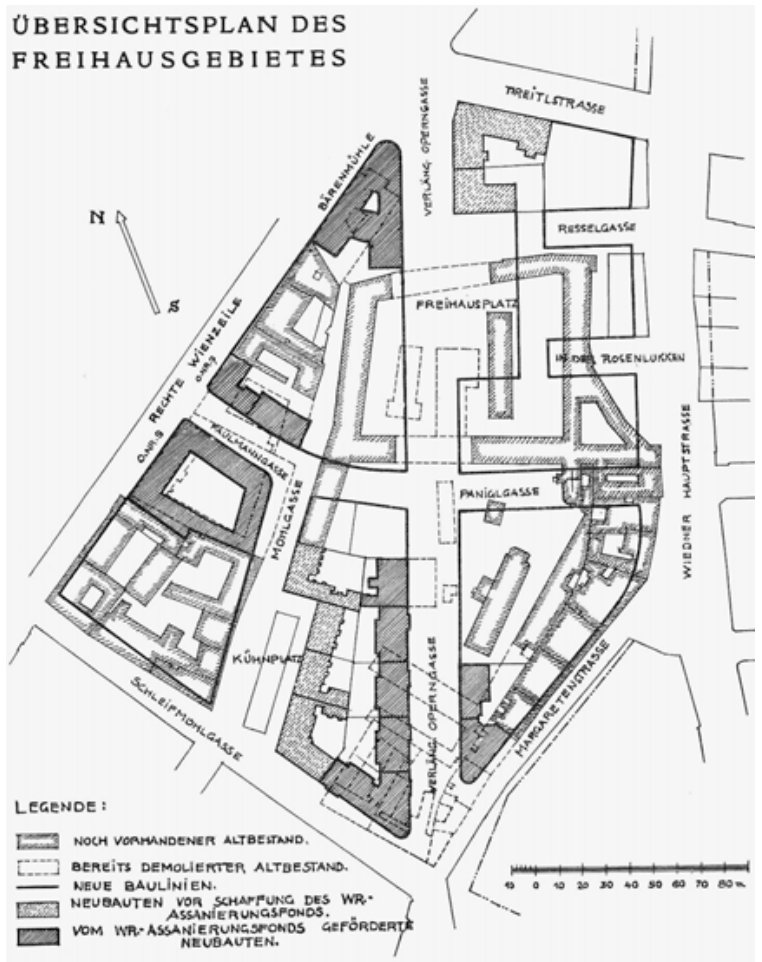

Abb. 71 Übersichtsplan des Assanierungsgebietes im Bereich des (teilweise bereits abgebrochenen) Freihauses, Abbruchstand 1937, hier in dunkelgrau die bereits errichteten Neubauten 


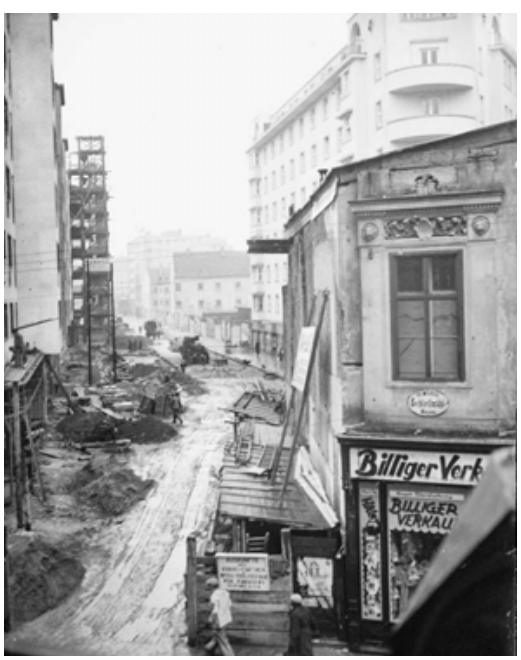

Abb. 72 Stockwerkaufnahme durch die auf den Freihausgründen entstehende verlängerte Operngasse, um 1935
Argumentiert wurde der Abbruch des Freihauses mit dem Bedarf an Verkehrsverbindungen und „hygienischeren Häusern".11 Trotz heftiger Kritik aus den Reihen der Verkehrsplaner und Architekten setzte man die Pläne in den 1930er-Jahren um. Die Architektenschaft sah sich in der Frage der Neubebauung der ehemaligen Freihausgründe übergangen und kritisierte die Ausführung der architektonisch und stadtplanerisch für sie unbefriedigenden Lösung. ${ }^{12}$ Die Kritik befasste sich in erster Linie mit dem vorliegenden Bebauungsplan, dem veralteten Verkehrskonzept und der geplanten Bebauungsstruktur, die nicht mehr den zeitgemäßen, hygienischen Anforderungen entsprachen. Kritische Stimmen waren vor allem die Österreichische Gesellschaft für Städtebau und der Ingenieur- und Architektenverein, die die Ausschreibung eines Wettbewerbs einforderten. ${ }^{\mathbf{1 3}}$ Die Freihauskontroverse war demnach vielmehr eine städtebaulich-architektonische als eine denkmalpflegerische, wenngleich auch hier durch den städtebaulichen Maßstab die zentrumsnahe Lage des Baugrundes und vor allem durch die vorhandene Bausubstanz des 18. Jahrhunderts Aspekte der Stadtbilderhaltung besonders relevant waren.

Mehrere Bauunternehmen investierten in der profitversprechenden Lage in unterschiedlich gestaltete und von verschiedenen Architekten geplante Neubauten. ${ }^{\mathbf{1 4}}$ Die Räumung des alten Freihauses war bis April 1936 abgeschlossen, am 1. Mai begann der schrittweise Abbruch. ${ }^{15}$ Mit der Demolierung der 150 Jahre alten Bausubstanz wurde an mehreren Stellen gleichzeitig begonnen (Abb. 70-72). ${ }^{16}$ Aufgrund der attraktiven Lage des Bauplatzes scheinen sowohl die Bauplatzvergabe an die Bauherren als auch die Wohnungsvermietung nach Fertigstellung der Neubauten kein Problem dargestellt zu haben. Die neuen Gebäude waren durch fast nahtlos aneinandergereihte Geschäftsräume in der Erdgeschosszone gekennzeichnet, die sechs Stockwerke darüber waren für kleine und mittelgroße Wohnungen vorgesehen. ${ }^{\mathbf{1 7}}$ Die neuen Prestigebauten an der Operngasse sollten auch den wirtschaftlichen Aufbruch symbolisieren. Gerade der Straßenzug Operngasse 26-36 verdeutlicht den angestrebten „großstädtischen Charakter", vermittelt durch die französischen Fenster, die modernen, ausklappbaren Holzrollos, die vollständig in Geschäftsflächen aufgelöste Erdgeschosszone und die verwendeten edlen Materialien in den Eingangsbereichen (siehe nochmals Abb. 68).

Die belebte Vergangenheit des Freihauses, die etwa mit Mozarts Zauberflöte eng verbunden war, versuchte man mit den Namen der Assanierungsbauten („Papagenohof“, Neubau zur Bärenmühle) zu bewahren. Auch die künstlerische Ausgestaltung nahm darauf Bezug, etwa durch Wandbilder in den Stiegenhäusern ${ }^{\mathbf{1 8}}$ oder durch spezielle Hauszeichen an den Fassaden (Wandreliefs, Wandmalereien oder Figurenschmuck; Abb. 73).

Die Erhaltung des Freihauses stand für die Zentralstelle für Denkmalschutz, bei allem Interesse für die bewegte Geschichte der Wohnhofanlage, offensichtlich nicht zur Debatte. Im Archiv des Bundesdenkmalamtes finden sich zum Abriss im Allgemeinen 


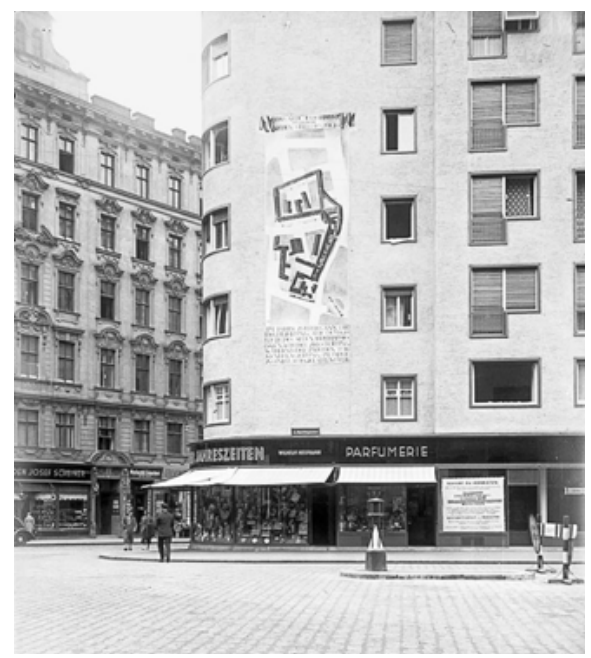

Abb. 73 Operngasse 36 mit Hauszeichen (Plan des alten Freihauses vor der Demolierung), 1937
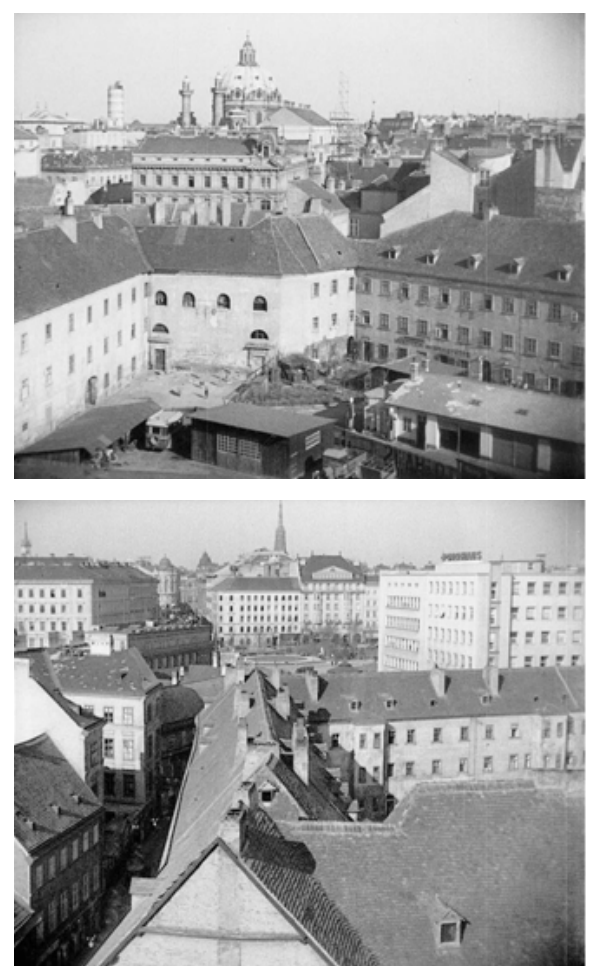

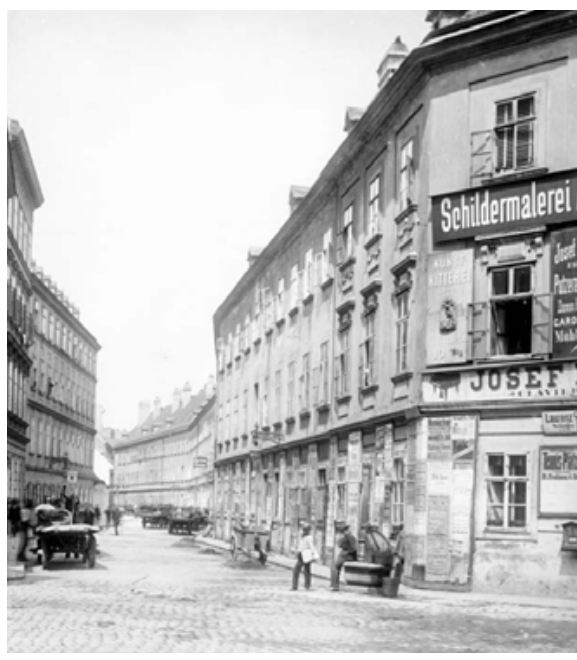

Abb. 74 August Stauda, Blick von der Schleifmühlgasse 16 Richtung Obstmarkt, rechts der damals noch bestehende Freihaus-Komplex, 1908
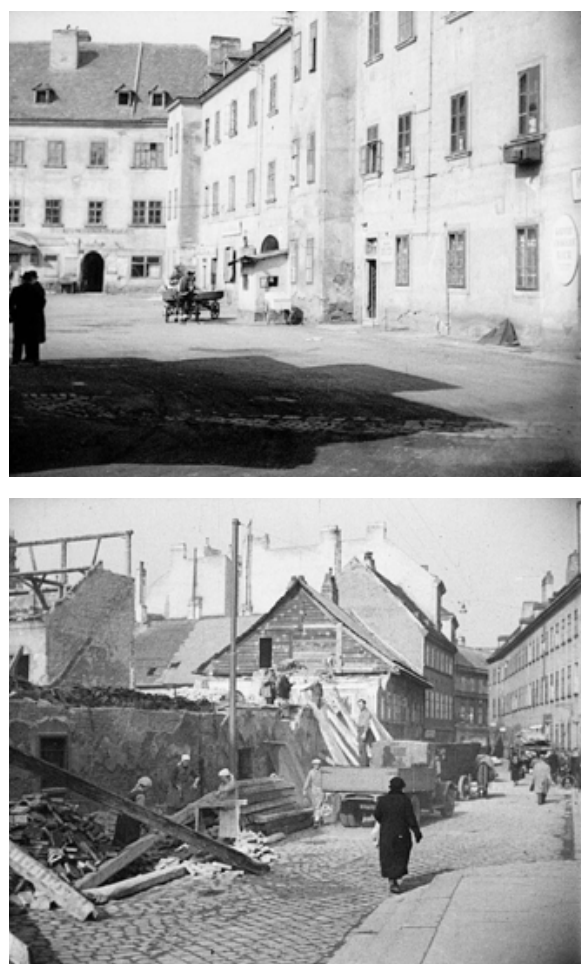

Abb. 75 Filmstills aus dem Kurzfilm Das Freihaus in Wien, 1936

kaum Unterlagen. Bei jedem geplanten Abbruch einzelner Parzellen fand durch die Referenten der Zentralstelle die gewohnte Prüfung statt. Die bestehende Bausubstanz wurde mitunter als „verwahrlost“19 beschrieben und grundsätzlich als wenig erhaltenswert klassifiziert (Abb. 74). Trotz der reichen Geschichte des Freihauses, wo 1791 
die Uraufführung von Mozarts Zauberflöte stattfand, wurde kein historischer Wert der Anlage festgestellt und lediglich die Erhaltung einer Marmorgedenktafel und mehrerer Stuckreliefs von der Fassade der alten Bärenmühle (siehe dazu nochmals Abb. 24) eingefordert. ${ }^{20}$ Die architektonische Bescheidenheit und der schlechte Erhaltungszustand des gesamten Komplexes sprachen damals gegen eine Erhaltung. Der historische Wert konnte dies nicht aufwiegen.

Die Bedeutung der Anlage verdeutlicht ein im Jahr 1936 produzierter Stummfilm, Das Freihaus in Wien. ${ }^{21}$ Der Film, dessen Entstehungsgeschichte, Auftraggeber und Produzent nicht bekannt sind, übt Kritik am zunehmenden Verlust eines ,an Geschichte reichen Stückes der Stadt Wien“ mit malerischen, aber auch finsteren und geheimnisvollen Winkeln, Höfen und Durchgängen. Er zeigt eine eigene idyllische, wenn auch ärmliche Welt im Zentrum einer Großstadt (Abb. 75). In zwischengeschalteten Kurztexten wird die Geschichte des Freihauses erläutert und das damalige Erscheinungsbild des ärmlichen Wohnquartiers charakterisiert:

„Mächtiges Mauerwerk und breite Einfahrten scheinen der Ewigkeit trotzen zu wollen und doch ist die Zeit nahe, da auch diese ausgedehnten Baulichkeiten beseitigt werden sollen, um neuzeitlichen Gebäuden Platz zu machen. Ein altes, an Geschichte reiches Stück der Stadt Wien verschwindet, um dem stets wachsenden Verkehr Platz zu machen.“22

Nach der Machtübernahme der Nationalsozialisten im Jahr 1938 waren noch immer Teile des alten Freihauses erhalten. Im Bereich zwischen Operngasse und Wiedner Hauptstraße sollte ein monumentales Reichsbahndirektionsgebäude errichtet werden, Pläne für den Neubau, der ,jene monumentalen Formen haben [sollte], die nationalsozialistischer Baugesinnung entsprechen“23, lagen bereits vor.

\subsubsection{Große Pläne für den Kahlenberg}

Auf dem Kahlenberg befand sich zu Beginn der 1930er-Jahre ein zum Teil stark vernachlässigtes Gebäudeensemble, bestehend aus der Kirche zum Hl. Josef, einem etwas heruntergekommenen Hotelrestaurant, erbaut im Zuge der Weltausstellung 1873, der historistischen Villa Braun-Stammfest sowie Gebäuden der 1874 fertiggestellten Zahnradbahn, deren Betrieb schon 1922 wieder eingestellt worden war (Abb. 76, 77). ${ }^{\mathbf{2 4}}$

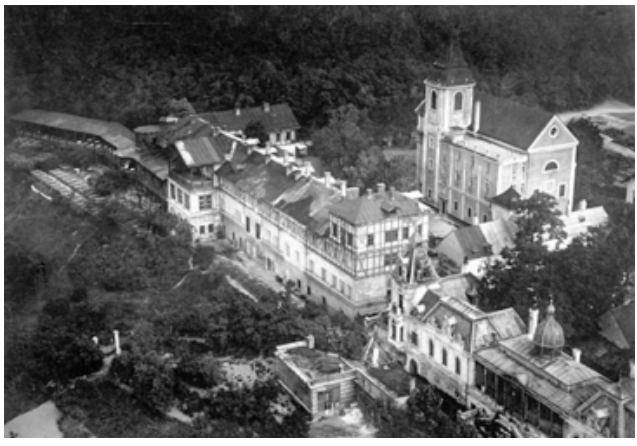

Abb. 76 Kirche und Restaurant am Kahlenberg, im Vordergrund die Villa Braun-Stammfest, Luftaufnahme, um 1930

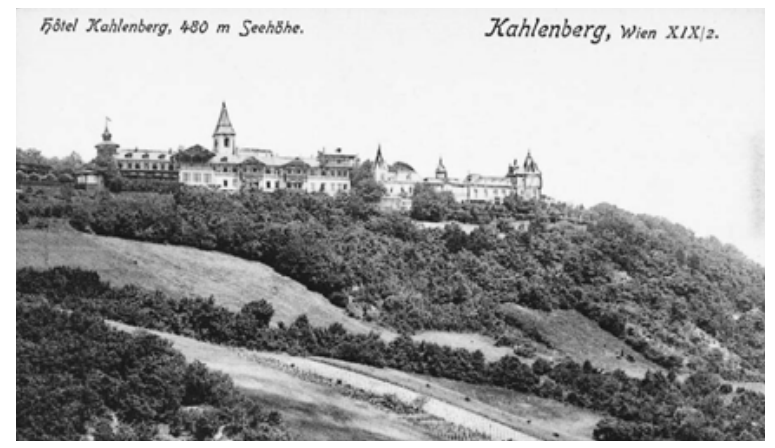

Abb. 77 Kahlenberg mit Restaurant (links) und Villa Braun-Stammfest (rechts), Ansichtskarte, 1909 
Bereits 1932 berichteten Tageszeitungen von einer geplanten „Wiederbelebung“ des Kahlenbergs. Die Gemeinde Wien hatte neben dem Restaurant auch die Aussichtswarte, einige Nebengebäude sowie die Trasse der alten Zahnradbahn zu angeblich äußerst günstigen Konditionen erworben. ${ }^{25}$ Nach einem Ideenwettbewerb für die Neugestaltung des Kahlenbergrestaurants wurden bereits im Frühjahr 1933 sechs Projekte preisgekrönt und noch im selben Jahr zu einem engeren Wettbewerb geladen. ${ }^{\mathbf{2 6}}$ Der Kahlenberg sollte also noch vor dem Ständestaat zu einem attraktiven Ausflugsziel für die Wiener Bevölkerung und die Gäste Wiens werden, aus politischen und wirtschaftlichen Gründen verzögerte sich allerdings die Verwirklichung. ${ }^{\mathbf{2 7}}$ Die Neugestaltung, vor allem der Bau der Höhenstraße, setzte erst nach 1934 ein und stellte sodann ein Prestigeprojekt der Stadt Wien dar und eine der zentralen Arbeitsbeschaffungsmaßnahmen. ${ }^{\mathbf{2 8}}$ Letztlich realisierte man Erich Boltensterns abgeänderten Entwurf, eine ursprünglich neben dem Restaurant geplante Badeanlage und der Festspielplatz wurden allerdings nicht ausgeführt (Abb. 78-80). ${ }^{29}$

Für den Wettbewerb konsultierte man auch die Zentralstelle für Denkmalschutz und holte Kriterien für die Ausschreibung ein. Aus Sicht der Behörde sollte vor allem „auf die Wirkung des Turmes und Gebäudes der [...] Kirche auf dem Kahlenberge im Ortsbilde von Josefsdorf und in der Landschaft möglichst Bedacht genommen werden“. Darüber hinaus galt als Vorgabe, dass bei der Anlage der Straße auch auf die unterirdischen Reste des Kamaldulenser-Klosters und den Friedhof Rücksicht genommen werden müsse. ${ }^{30}$

Dem Neubau mussten das alte Hotelrestaurant weichen sowie für die ausladende Aussichtsterrasse auch die Villa Braun-Stammfest, errichtet um 1880 (Abb. 81, 82), die angeblich ohnehin baufällig war. ${ }^{\mathbf{3 1}}$ Die Villa, eine imposante, breit gelagerte historistische Anlage, mit ihrer Schaufront zur Stadt ausgerichtet, mit weitläufiger Parkanlage, ausladender Freitreppe und mittig gelegenem Wintergarten, wurde von der Zentralstelle als künstlerisch wertlos und uninteressant erachtet, weshalb man gegen den Abriss auch keinen Einwand erhob. ${ }^{32}$ Lediglich einzelne wertvolle Einrichtungsgegenstände und Teile der festen Ausstattung, wie Wandverkleidungen und Kassettendecken, sollten erhalten werden. ${ }^{\mathbf{3 3}}$ An der Erhaltung des Gebäudes an sich, wenngleich die Villa auch von besonderer architektonischer Qualität war, zeigte die Zentralstelle keinerlei Interesse. Man war vor allem um die Fernwirkung der Kirche besorgt und begrüßte daher die geringe Höhe des Neubaus. ${ }^{\mathbf{3 4}}$

Die Abrisstätigkeit auf dem Kahlenberg fand also auch durch den Denkmalschutz Unterstützung. Die Stadt beabsichtigte eine repräsentative, mondäne Ausgestaltung des Kahlenbergs, der - nach damaliger Wahrnehmung - lediglich unbedeutende Gebäude des 19. Jahrhunderts weichen mussten und die somit kaum Kritik hervorrief. Dem Prestigeprojekt der Stadt Wien mussten aber nicht nur auf dem Kahlenberg bauliche Opfer gebracht werden. Im Zuge des Baus der Höhenstraße waren auch Regulierungs- und Abbruchmaßnahmen in den Zubringerstraßen vorgesehen, etwa im Bereich der Billrothstraße (siehe dazu auch Kap. 3.1.2.). ${ }^{35}$ Dieser geplanten Abrisstätigkeit in den Ausläufern der Stadt standen die Zentralstelle und die Öffentlichkeit sehr kritisch gegenüber. Wie bereits ausgeführt, setzte man sich vor allem für die Erhaltung des Ortsbildes von Grinzing energisch ein. 


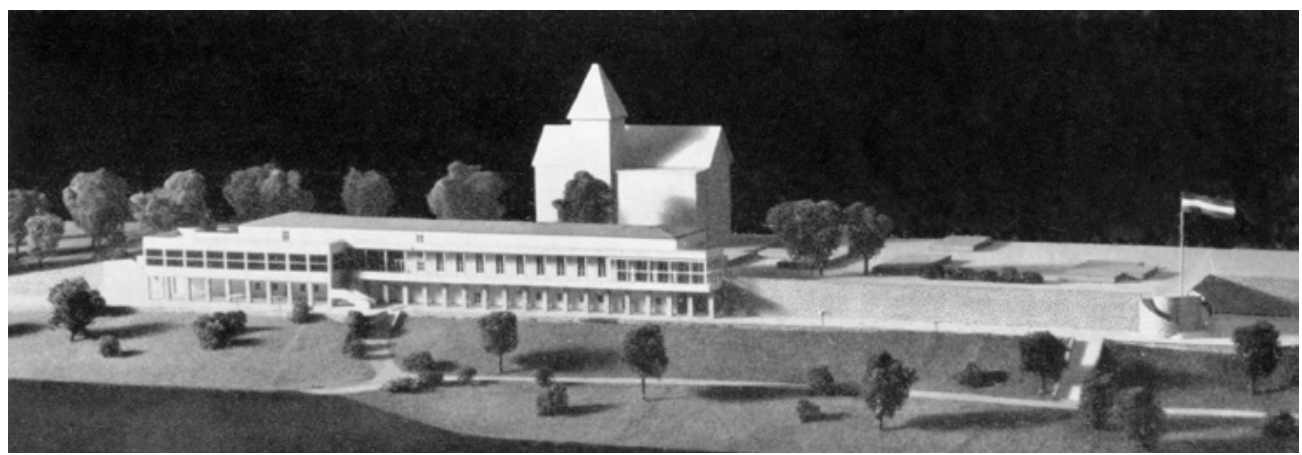

Abb.78 Erich Boltenstern, Restaurant am Kahlenberg mit weitläufiger Aussichtsterrasse, Modell, vermutlich 1933
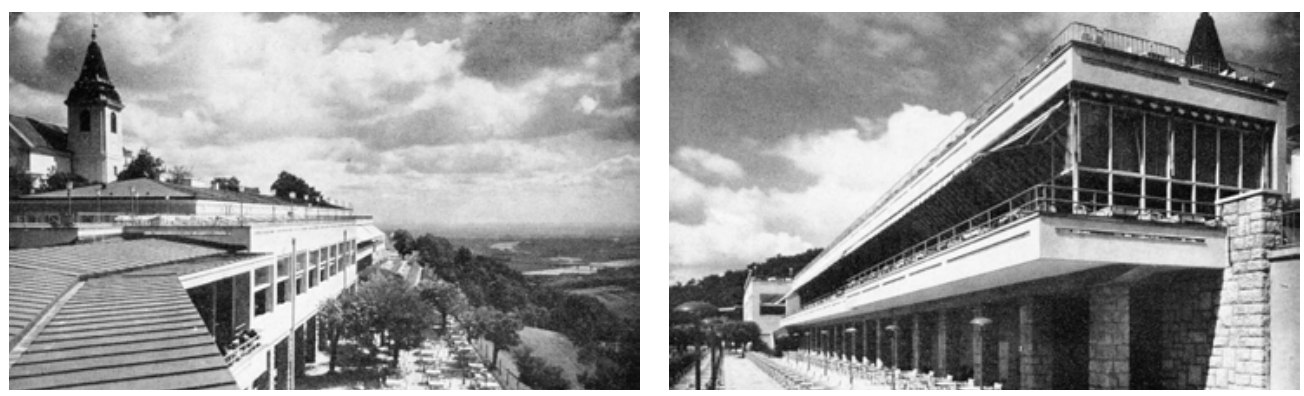

Abb. 79 und 80 Restaurant am Kahlenberg nach der Fertigstellung, Aufnahmen vermutlich 1936

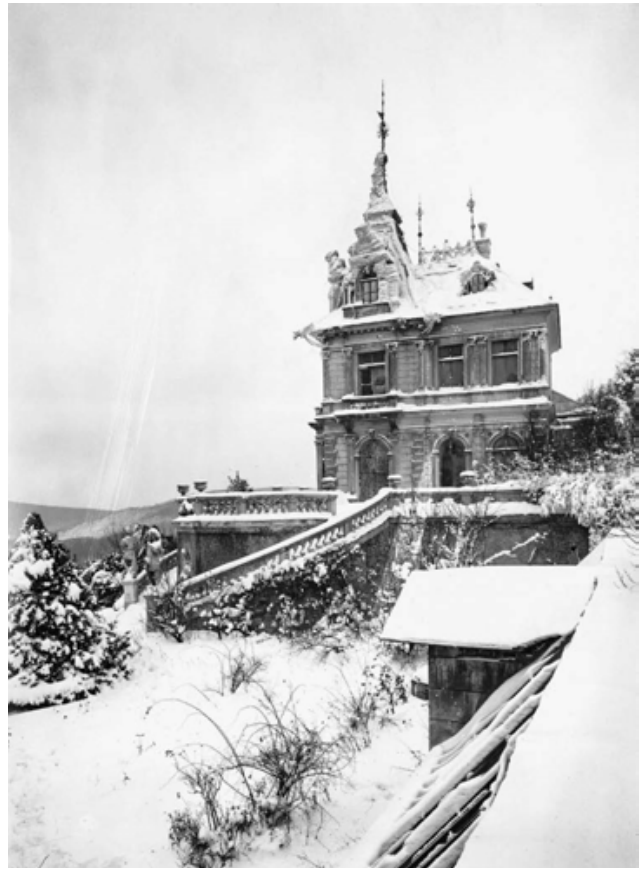

Abb. 81 Villa Braun-Stammfest, Seitenansicht, Aufnahme 1933

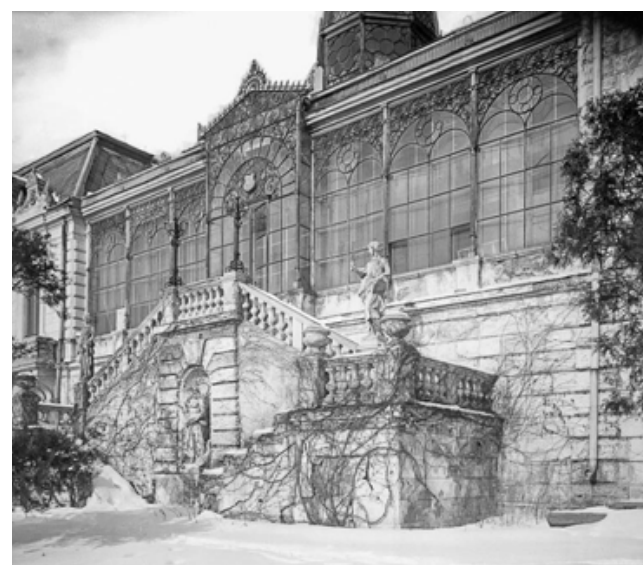

Abb. 82 Villa Braun-Stammfest, Gartenfront, Aufnahme 1935 


\subsubsection{Das Palais Paar und die Begradigung der Wollzeile}

Im Gegensatz zur Architektur des Historismus wurde jener des Barock in der Zwischenkriegszeit bereits große Wertschätzung entgegengebracht. Schon die Österreichische Kunsttopographie bezeichnete das Palais Paar in der Wollzeile 30 als einen der „hervorragendsten Paläste der Stadt“. Das durch sein markantes Hauptgeschoss und die nicht zentrierte Ausrichtung der Fassade sehr eigentümliche Barockpalais galt als ältestes Postgebäude Europas (Abb. 83). ${ }^{\mathbf{3 6}}$ Wie auch das angrenzende Gebäude Wollzeile 32, „gleichfalls ein hervorragender Bau“37 des 18. Jahrhunderts, sollte es aus einer angeblichen städtebaulichen Notwendigkeit heraus abgetragen werden. Die Wollzeile galt als Teil einer wesentlichen Verkehrsachse durch die dicht bebaute Innenstadt und sollte deshalb, so die Auffassung der Stadtverwaltung, begradigt werden (Abb. 84).

Vor allem in den Jahren 1937 und 1938 wurde die Frage um die Zukunft des Palais Paar von Fachleuten sowie der Öffentlichkeit rege diskutiert. Den erhaltenen Akten zufolge stellte die Zentralstelle das Palais Paar bereits 1924 aufgrund ,seiner geschichtlichen, künstlerischen und kulturellen Bedeutung“ unter Schutz. ${ }^{\mathbf{3 8}}$ Trotz der bestehenden Unterschutzstellung wandte sich im Jänner 1936 der Assanierungsfonds an die Zentralstelle mit der Bitte um Stellungnahme, da ein Ansuchen um „Umbau“ des Palais eingelangt war. Die Anfrage wurde von der Zentralstelle, mit Verweis auf die Unterschutzstellung und die Bedeutung des Palais, das „mit seiner bemerkenswerten Barockfassade und seinen Innenräumen zu den künstlerisch bemerkenswertesten Barockpalästen Wiens“ gehöre, abgewiesen. ${ }^{39}$

Im Februar 1937 stellte Otto Demus fest, dass das Palais und das Nachbarhaus Wollzeile 32 „zu den besten Bauten dieses Stadtteiles“ gehörten und daher „alles zu versuchen [sei], um das Bauwerk unverändert zu erhalten“.40 Auch der vermutlich 1937 gegründete „Fachbeirat für Fragen des Bauwesens auf dem Gebiete der Denkmalpflege“, dem neben Emmerich Siegris, Sektionschef Petrin und Herbert Seiberl (Schriftführer) auch Clemens Holzmeister, Karl Holey und Karl Kraus angehörten, sprach sich im selben Jahr einstimmig für die Erhaltung des Palais Paar aus. Holey zufolge war ein Abbruch aus städtebaulichen Gründen nicht not-

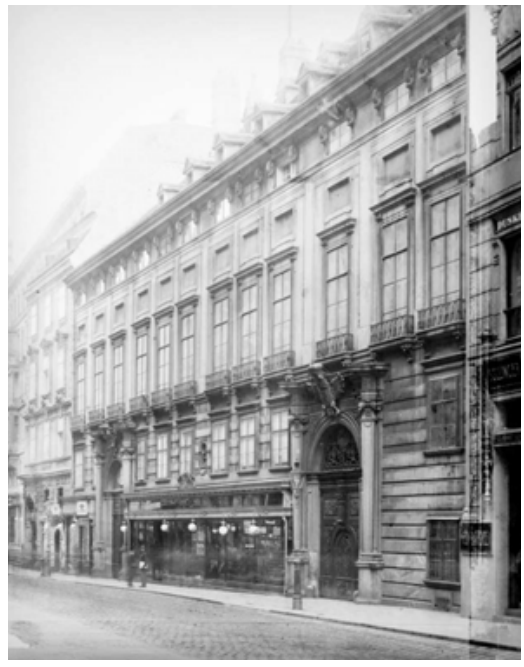

Abb. 83 August Stauda, Palais Paar, Fassade, Aufnahme 1907 wendig, stattdessen könne man „ähnlich wie dies in Deutschland und in der Cechoslovakei [sic!] häufig geschehe, unter Erhaltung der Fassade im Inneren eine völlige Umgestaltung vornehmen“"41

Im September 1937 erfolgte eine erneute Anfrage des Assanierungsfonds, wobei man auf die Dringlichkeit der verkehrstechnischen Regulierung der Wollzeile verwies. Daraufhin meldete die Zentralstelle zurück, dass unter Einschränkungen ein Teilabriss nun doch möglich sei und schlug im Sinne Holeys eine „Entkernung" vor. ${ }^{\mathbf{2 2}}$ Die Zentralstelle versuchte weiterhin, mit Verweis auf den Stimmungswert und die künstlerische Bedeutung des gesamten Stadtteiles, dem Bestreben der Stadtverwaltung standzuhalten. Im Oktober 1937 verwies man in einem neuerlichen Schreiben mit Nachdruck darauf, dass eine Regulierung der Wollzeile das Verkehrsproblem nicht lösen, sondern auch 


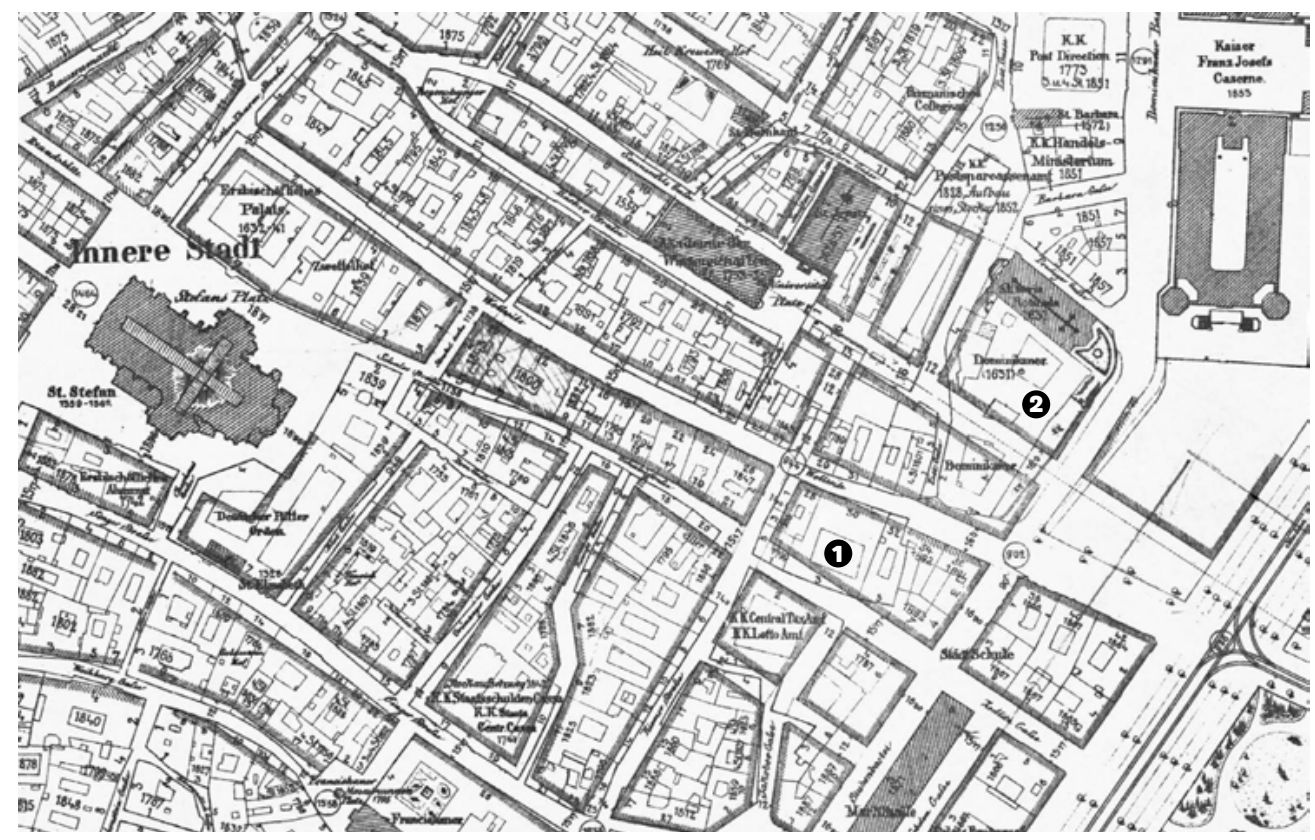

Abb. 84 Generalregulierungsplan, Ausschnitt Wollzeile mit vorgesehener Regulierung, davon betroffen u.a. das Palais Paar (1) und das Dominikanerkonvent (2), 1892

eine Regulierung der Bäckerstraße nach sich ziehen und damit Auswirkungen auf das Stadtbild und den Ensemblecharakter eines der ältesten Teile Wiens nehmen würde:

„Die Bäckerstraße aber bildet im Verein mit der Sonnenfels- und der Schönlaterngasse und dem Universitätsplatz, dem schönsten Platze Wiens, den letzten kleinen Rest der Wiener Altstadt, der sich geschlossen erhalten hat. Dieser an sich ganz kleine Stadtteil ist voll von prächtigen alten Bauten und enthält eine Fülle malerischer, ungemein stimmungsvoller Straßenansichten. Wohl nirgends ist so wie hier der Hauch der großen ruhmreichen Vergangenheit Wiens so unmittelbar zu empfinden. Die Demolierung eines einzigen Hauses, geschweige denn die Eröffnung einer großen Verkehrsstraße würde den ganzen Zauber, der über diesem Stadtteil liegt unwiederbringlich zerstören [...].“43

Diesen Anmerkungen zuwider wurde im November 1937 von der Zentralstelle plötzlich die Zustimmung für den „Umbau“ des Palais Paar und des Nachbargebäudes erteilt. Dieser Entscheidung war eine Weisung aus dem Bundesministerium für Unterricht vorausgegangen. ${ }^{\mathbf{4 4}}$ Bürgermeister Schmitz persönlich hatte in einem Schreiben an den Bundesminister auf die Dringlichkeit der Demolierung hingewiesen und um Bewilligung der Abtragung ersucht. Diese Entscheidung musste die Denkmalschutzbehörde hinnehmen, man ergriff auch keine weiteren Initiativen. ${ }^{\mathbf{4 5}}$ Es blieb der Zentralstelle nur noch der Versuch, in Abstimmung mit dem Museum der Stadt Wien und den Städtischen Sammlungen, die Kunstgegenstände im Palais Paar und die wertvollen Stuckreliefs aus dem Marstall zu retten, ehe im Jänner 1938, unter Protest der Öffentlichkeit, mit den Abbrucharbeiten begonnen wurde. ${ }^{\mathbf{4 6}}$ 


\subsubsection{Stadtbildverlust an der Dominikanerbastei}

Anhand der Diskussionen um ein weiteres Gebäude in der Wollzeile kann die schwierige Position der Zentralstelle für Denkmalschutz besonders anschaulich dargestellt werden. Der schlichte, viergeschossige Baukörper des Dominikanerklosters (Abb. 85) erstreckte sich auf unregelmäßigem Grundriss zwischen Wollzeile, Postgasse und der Dominikanerbastei (siehe dazu auch nochmals Abb. 84). Von Weitem kennzeichnete das ausladende Gebäude mit schlichter, kaum gegliederter Fassade der markante Schlosserturm (Abb. 86). Wie auch das Palais Paar missfiel der Stadtverwaltung der im 17. Jahrhundert erbaute Komplex aus verkehrstechnischen Gründen. Wie der Generalstadtplan zeigt, plante man neben der Begradigung der Wollzeile auch einen Durchbruch von der Dominikanerbastei zur Bäckerstraße und zum alten Universitätsplatz. ${ }^{47}$

Ende des Jahres 1936 trat die Zentralstelle entschieden dafür ein, das Gebäude, das als Liegenschaft im Besitz einer Glaubensgemeinschaft schon damals unter Schutz stand, vollumfänglich zu erhalten.48 Der Abbruch würde „einen schweren Verlust für das Stadtbild bedeuten“ und auch die Bewilligung des Projektes „in der Öffentlichkeit nicht verstanden werden“. Mit noch drastischeren Worten wandte sich Karl Ginhart an das Wiener Rathaus:

„Jede Veränderung [...] wäre ein derart weitgehender Eingriff in das historisch erhaltenswerte alte Wiener Stadtbild und der Dominikanerbastei, daß jede, wenn auch eventuell nur teilweise Demolierung auf den entschiedenen Widerstand aller Freunde des anerkannt schönen Wiener Stadtbildes stoßen müßte. In der gesamten Öffentlichkeit würde ein berechtigter Sturm der Entrüstung gegen dieses Bauvorhaben ausbrechen."49

Doch einem neuerlichen Umbauantrag des Dominikanerkonvents, der lediglich die Veränderung des rückwärtigen Traktes zur Postgasse und des Seitentraktes zur Wollzeile unter Beibehaltung der gesamten Front zum Dr.-Karl-Lueger-Platz beinhaltete, stimmte die Zentralstelle unter der Bedingung zu, dass auch der markante Schlosserturm, das Portal des Einganges zur ehemaligen Windhag'schen Bibliothek und die

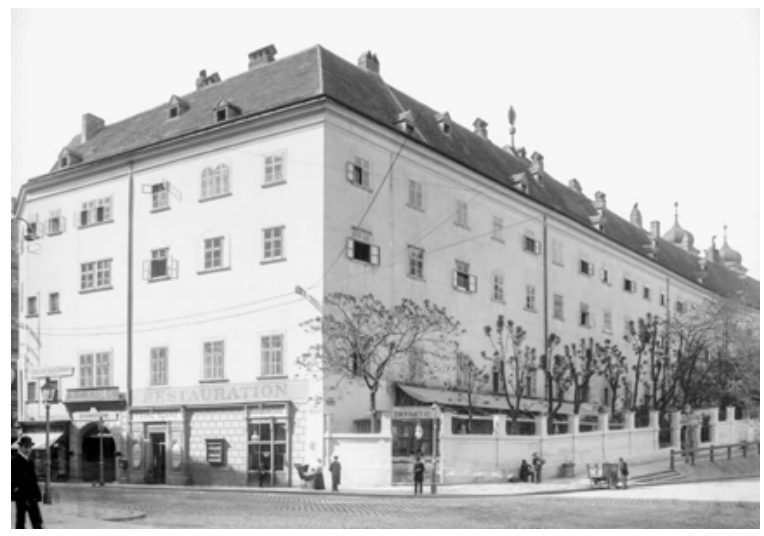

Abb. 85 August Stauda, Dominikanerkonvent an der Dominikanerbastei, Aufnahme 1905
Basteimauern und somit „das Platzbild der Dominikanerbastei“" weitgehend erhalten blieben. ${ }^{\mathbf{5 0}}$ Die Zentralstelle erteilte also im Sinne einer Kompromisslösung ihre Zustimmung für den Teilabriss der Klosteranlage.

Im Februar 1937 änderten sich die Rahmenbedingungen maßgeblich, da der Assanierungsfonds den Umbau als nicht wirtschaftlich erachtete und einen geringeren Zuschuss bewilligte. Der Konvent trat daher neuerlich an die Zentralstelle heran und bat, mit Verweis auf die finanzielle Notlage des Ordens, um Zustim- 
mung, das ursprünglich geplante und radikalere Projekt umsetzen zu dürfen, das den Umbau des gesamten Gebäudes zwischen Dr.-Karl-Lueger-Platz und Wollzeile umfasste und von dem man sich eine höhere Rentabilität erwarten konnte. ${ }^{\mathbf{5 1}}$ Die Zentralstelle, in der Person von Leodegar Petrin, reagierte empört, war man dem Konvent doch bereits sehr weit entgegengekommen:

„Nicht nur, dass wir Ihnen den weitgehenden Umbau des rückwärtigen Traktes in der Postgasse bewilligten und dabei auch

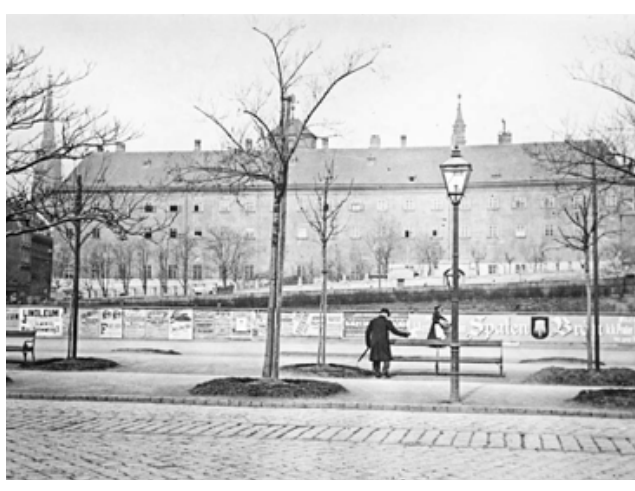

Abb. 86 Dominikanerkloster mit Schlosserturm (mittig im Bild), Blick vom Stubenring, 1896 den Durchgang konzedierten, der das Bild der Bastei weitgehend tangieren wird, es wurde Ihnen auch in überaus entgegenkommender Weise - ich möchte fast sagen, gegen unser besseres Gewissen - die Adaptierung der Parterreräumlichkeiten für den Restaurationsbetrieb und die Beseitigung des vorliegenden Endteiles der Bastei bewilligt. [...] Ich hatte schon die Absicht, Ihnen gleich zu schreiben, [...] dass wir nicht gesonnen sind, auch bei solchen weitreichenden Plänen uns willfährig zu erweisen.“52

Die im Februar 1937 vorgelegten neuen Umbaupläne der Architekten Kurt Klaudy, Georg Lippert und Anton Liebe sahen in der Wahrnehmung der Zentralstelle eine derart radikale Veränderung vor, dass „,vom Ring aus gesehen so ziemlich jede Erinnerung an die Bastei vollständig verschwinden, [...] und das gesamte Stadtbild beim ehemaligen Stubentor hiedurch in der einschneidendsten Weise verändert würde“.53 Mit dieser Einschätzung und dem Hinweis auf die Undurchführbarkeit der Pläne wandte sich Petrin persönlich an den Bürgermeister und den Vizebürgermeister der Stadt Wien:

„Es wäre der Anfang vom Ende des ganzen alten Stadtteiles zwischen Stubentor und Lugeck, der uns allen ans Herz gewachsen [...] ist. Wien verdankt seine Anziehungskraft für Ausländer nicht zuletzt dem Umstande, dass es heute noch eine altehrwürdige Stadt ist, die sich von den schablonenhaften Neubauten anderer Grosstädte [sic!] in wohltuendster Weise abhebt. Wenn wir auf den leider seit einigen Jahren so vielfach betretenen Pfaden der Ausmerzung alter Stadtbilder noch einige Zeit fortschreiten, so wird Wien eine Grosstadt [sic!] werden wie viele andere [...]."54

Unmissverständlich kommen in diesen Zeilen der seit Langem wachsende Unmut des Beamten über die umfangreichen Regulierungsmaßnahmen der Stadtverwaltung und die Besorgnis um den fortschreitenden Verlust der architektonischen Eigenart Wiens zum Ausdruck. Im März 1937 berief Petrin schlussendlich den „Fachbeirat für Fragen des Bauwesens auf dem Gebiete der Denkmalpflege“55 ein. In dieser Sitzung wurden wesentliche Auflagen für die Gestaltung des Neubaus schriftlich ausgearbeitet, die man in weiterer Folge auch dem Bürgermeister übermittelte. ${ }^{\mathbf{5 6}}$ Der „,bestehende Charakter des Platzbildes und seines Abschlusses“ müsse erhalten bleiben, der Neubau sich in seiner Gestaltung an das bestehende Gebäude angleichen, vor allem 


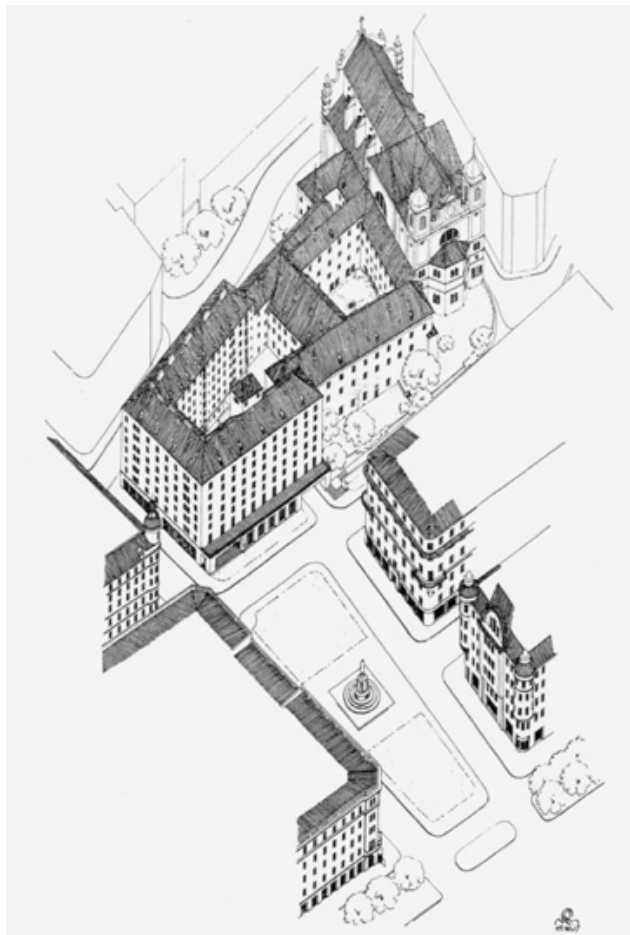

Abb. 87 Kurt Klaudy, Georg Lippert und Anton Liebe, Dominikaner-Neubau in seiner neuen, städtebaulichen Situation, 1937

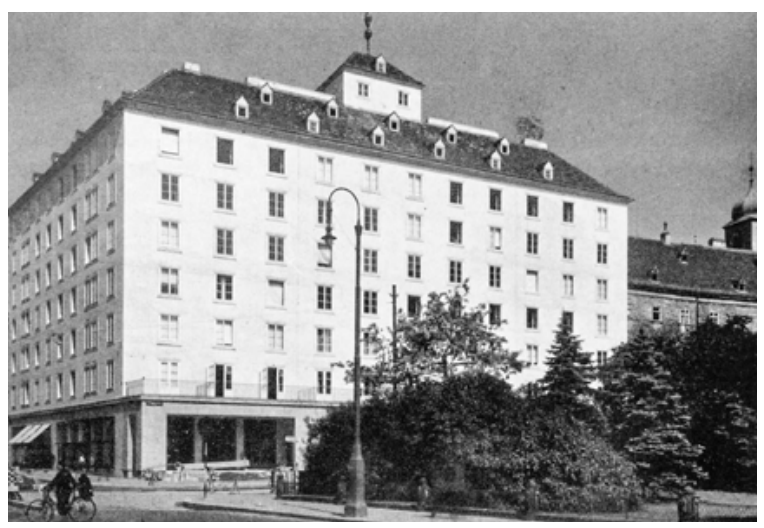

Abb. 88 Kurt Klaudy, Georg Lippert und Anton Liebe, Ansicht des gerade fertiggestellten Dominikaner-Neubaus, 1938

hinsichtlich des Verhältnisses von Fensterund naturfarbig verputzten Wandflächen. Die Ausführung der Fensterumrahmungen, der Gesimse und des Sockels sollte in Werkstein geschehen, auch die Dachdeckung dürfe die „Harmonie des Platzes“ nicht stören.57

Unter diesen Auflagen stimmte die Zentralstelle im April desselben Jahres einem Totalumbau zu. Bei einer Sitzung im Wiener Rathaus stellte man fest, dass „vornehmlich aus

finanziellen Erwägungen der Umbau des Dominikanerklosters bedauerlicherweise nicht verhindert werden“ könne. Diese plötzliche Kursänderung scheint auf den von Ordensseite und auch vonseiten des Stadtbauamtes ausgeübten Druck zurückzuführen zu sein. Die Gestaltungsauflagen für den Neubau wurden schließlich noch um einige weitere Punkte ergänzt: Beispielsweise einigte man sich auf die Neuerrichtung des stadtbildprägenden Schlosserturms. Auf Vorbauten wie Erker musste verzichtet und die Dachdeckung sollte möglichst aus altem Ziegelbestand hergestellt werden. ${ }^{\mathbf{5 8}}$ Die Erhaltung des barocken Refektoriums mit seinen wertvollen Stuckaturen und Deckenfresken und seine Integration in den Neubau konnte von der Zentralstelle letztlich nicht durchgesetzt werden. ${ }^{\mathbf{5 9}}$ Sowohl der Prior des Dominikanerordens als auch Stadtbaudirektor Musil sprachen sich aus wirtschaftlichen Gründen gegen die Erhaltung aus. ${ }^{60}$ Die Zentralstelle musste sich somit in diesem Falle nicht nur der Auffassung der Verkehrs- und Stadtplaner, sondern auch ökonomischen Überlegungen beugen. Im Juli 1937 begannen schließlich die Abbrucharbeiten. ${ }^{61}$ Der Neubau nach Plänen von Kurt Klaudy, Georg Lippert und Anton Liebe versucht, das alte Stadtbild, die Stadtsilhouette hin zum 3. Bezirk, mit der Front des Klosters und dem markanten Schlosserturm, nachzuempfinden (Abb. 87, 88). Letztlich aber bleibt es, allein durch die Dimensionen des Neubaus, bei einem entfremdeten Zitat. ${ }^{62}$ Im Sinne einer aktiven Stadtbildpflege versuchte die Zentralstelle im Falle des Dominikanerklosters in die Gestaltung des Neubaus einzugreifen. Da die Erhaltung des historischen Klosters nicht möglich war, gab man die Gestaltung des Neubaus weitgehend vor. 
Vor allem über das Palais Paar und den Neubau des Dominikanerklosters wurde in der Öffentlichkeit heftig und teils kontrovers diskutiert. In der öffentlichen Wahrnehmung wuchs dabei das Unverständnis für das Vorgehen der städtischen Verwaltung und andererseits auch der Eindruck der Untätigkeit und „Zahnlosigkeit“ der Denkmalpflege. Nachvollziehbar wird dies anhand der Aktenvermerke der Referenten der Zentralstelle und der zahlreichen Zuschriften von Privatpersonen, die die Denkmalschutzbehörde im Jahr 1937 und im Frühjahr 1938 erreichten. ${ }^{63}$ Auch Stadtverwaltung und Bürgermeister gerieten immer stärker unter Druck, was Letzteren schließlich dazu bewegte, Ende des Jahres 1937 die Bildung einer Expertenkommission zur Prüfung der städtebaulichen Fragen und zur Überarbeitung des Generalregulierungsplanes zu veranlassen.

\subsection{Stimmen zur Assanierung - von Befürwortung bis Widerstand}

Fragen der Stadtregulierung und Stadterhaltung wurden nicht nur von der institutionellen Denkmalpflege und der Stadtverwaltung diskutiert. In den denkmalpflegerischen und städtebaulichen Diskurs zwischen den „Stadtbewahrern“ und „Stadterneuerern" war in den 1930er-Jahren ein Kreis an Fachleuten involviert. Einige Namen begegnen besonders häufig, wie Karl Holey, Clemens Holzmeister, Hugo Hassinger und Robert Oerley. Sie bezogen öffentlich Stellung, kommentierten bereits durchgeführte oder geplante Maßnahmen in entsprechenden Fachperiodika, Tageszeitungen oder in Vorträgen und waren in Vereinen oder Interessengemeinschaften aktiv.

Die Quellen im Archiv des Bundesdenkmalamtes (Briefe und Zeitungsartikel) vermitteln einen guten Eindruck über die emotionale Stimmung in der (Fach-)Öffentlichkeit, vor allem gegen Ende des Jahres 1937. Während die Fachkreise in erster Linie auf den Verlust kulturell und historisch bedeutsamer Objekte verwiesen und man auf der gegnerischen Seite die Notwendigkeit der Regulierung und "Stadtbildverbesserung“ betonte, kennzeichnete die privaten Zusendungen an die Zentralstelle und die Zeitungsberichte ein zumeist sehr emotional vorgetragenes und eindringliches Ersuchen, sich doch nun endlich um den Erhalt des „alt-ehrwürdigen Wien“ zu bemühen, das zunehmend an Charakter einbüße. ${ }^{64}$

\subsubsection{Die Planenden - freischaffende Architektenschaft}

Aus den Reihen der Architekten und Stadtplaner vernahm man natürlich auch positive Stimmen zu geplanten und durchgeführten Regulierungsmaßnahmen, denn von der Förderung der Bautätigkeit erhofften sich diese eine Verbesserung der seit Jahren schlechten Auftragslage. Auch selbst ergriff man Initiativen, um die private Bautätigkeit wieder anzukurbeln (siehe dazu auch Kap. 2.2). Mehrfach wandte sich die Zentralvereinigung der Architekten an das Stadtbauamt, forderte die Unterstützung ihres Berufsstandes und erbat, die Architekturschaffenden stärker in Bau- und Regulierungsfragen miteinzubeziehen. ${ }^{65}$ Im Jahr 1937 bot man an, den von der Stadtverwaltung noch immer als Planungsgrundlage verwendeten und stark in der Kritik stehenden Generalregulierungsplan zu überarbeiten. In Form eines Wettbewerbes unter den „städtebaulich erfahrenen Architekten der Zentralvereinigung“ und in Zusammenarbeit mit dem Stadtbauamt solle ein neuer, zeitgemäßer Generalstadtplan erstellt werden, der eine „klare zielbewusste Entwicklung der Stadt, das Vermeiden von fallweise erzwungenen Verlegenheitslösungen und die einwandfreie Festlegung von 
beabsichtigten Veränderungen im Stadtbild im Gegensatz zu den unberührt bleibenden Teilen der Stadt" möglich machen sollte. ${ }^{\mathbf{6 6}}$ Bereits im Jahr davor hatte man sich gemeinsam mit dem Österreichischen Ingenieur- und Architektenverein und der Österreichischen Gesellschaft für Städtebau - also als die „gesamte Technikerschaft“ - mit der Bitte an den Bürgermeister gewandt, im Sinne eines Mitwirkens an der „Verwirklichung des Ständestaats“, auch in wichtige Fragen des Städtebaus und der Bauordnung miteinbezogen zu werden. ${ }^{\mathbf{6 7}}$

In einem Artikel der Reichspost von 1934 meldeten sich vier „hervorragende Wiener Baukünstler" zur aktuellen Situation von Architektur und Städtebau in Wien und zu dringenden Bauaufgaben „ihrer Zeit“ zu Wort: Karl Holey, Clemens Holzmeister, Siegfried Theiss und Robert Kramreiter.68 ${ }^{\mathbf{6 8}}$ Sie waren wohl auch jene, die in den folgenden Jahren nicht nur zahlreiche Aufträge erhielten, sondern auch den größten Einfluss auf die Bautätigkeit im Ständestaat nahmen. Vor allem auf Karl Holey werden wir im Folgenden noch öfter zurückkommen. Während Holey von einem neuen Stadtzentrum am rechten Donauufer schwärmte, einer „vom Geiste des neuen Städtebaus zeugende[n] Geschäftsstadt mit Promenaden, breiten Uferstraßen, Gartenanlagen, modernen Verkehrsanlagen und einzelnen architektonischen Dominanten längs des Ufers“, und Holzmeister Vorschläge für städtebauliche Verbesserungen entlang der Ringstraße brachte, befasste sich der „Kirchenbauer“ Kramreiter mit den (immer) noch ungelösten - und damals viel diskutierten - „Problembereichen“ um die Karlskirche und Votivkirche. Der Beitrag von Siegfried Theiss erweist sich hier jedoch als der interessanteste, da er darin zu generellen Fragen des Städtebaus Stellung bezieht, unter anderem zu der auch ,in anderen Kulturstaaten [...] lebhaft behandelte[n] Frage der Altstadterneuerung“. Hinsichtlich der Altstadterneuerung habe die Gemeinde Wien mit Bürgermeister Schmitz durch gesetzliche Bestimmungen „schon vorgearbeitet“, dem nun eine großzügige Stadterneuerung folgen müsse. „Überalterte“ Gebäude müssten den neuen Bauten weichen, der Denkmalschutz dürfe „nicht auch auf Mittelmäßiges ausgedehnt werden“.69

Viele Architekten befürworteten also die städtebaulichen Regulierungsprojekte, ließ sich davon doch eine erhebliche Verbesserung der wirtschaftlichen Situation erwarten. Dennoch gab es unter den Architekten auch Kritiker, die sich spätestens im Jänner 1938 als Unterzeichner der bereits erwähnten Unterschriftenaktion zur „Rettung von Alt-Wien“ zu erkennen gaben. ${ }^{70}$ Die Rolle Clemens Holzmeisters ist unter den Architekten im Ständestaat mit Sicherheit die interessanteste. ${ }^{\mathbf{1 1}}$ Durch seine Funktionen als Bundeskulturrat, Präsident der Zentralvereinigung der Architekten und Vorsitzender des Österreichischen Werkbundes und durch seine Tätigkeit als Professor und später auch Rektor der Akademie der bildenden Künste war er im öffentlichen und kulturellen Leben sehr präsent und auch politisch einflussreich. ${ }^{\mathbf{2}}$ Seine Bedeutung für die Konzeption der Arbeitsbeschaffungsmaßnahmen wurde in Kapitel 2 bereits angesprochen. In den frühen 1930er-Jahren stand er der Assanierung noch sehr positiv gegenüber.

Eine auffällige Figur war auch Robert Oerley. Eigentlich ausgebildeter Tischler und Maler und als Architekt nahezu Autodidakt, hatte er sich aber an der Seite von Holzmeister in Ankara internationale Bekanntschaft erarbeitet. 1934 war er - nach einigen prestigeträchtigen Aufträgen in der Türkei und Unstimmigkeiten mit Holzmeister - nach Wien zurückgekehrt und musste sich fortan mit kleineren Aufträgen begnügen. 1935 
berief man ihn allerdings in den Fachbeirat für Stadtplanung. ${ }^{\mathbf{7 3}}$ Sein Name begegnet in den Tageszeitungen der 1930er-Jahre überdurchschnittlich oft. 1936 äußerte er etwa utopische Ideen, wie jene eines unterirdischen Straßenkreuzes unter dem 1. Bezirk und einer zweigeschossigen Straßenführung. Stärker der Realität verhaftet war hingegen sein Vorschlag, die „im Wege stehenden Häuserecken“ abzurunden („wegzuoperieren“) und zwei Drittel aller Straßen zu Wohnstraßen zu erklären. Für die Mietkasernen-Viertel in Simmering und Ottakring schlug er eine „Auskernung“ der Innenhöfe und Anlage von Gärten vor. ${ }^{\mathbf{7 4}}$ Im Rahmen der 15. Österreichischen Bundestagung für Heimatpflege 1936 in Wiener Neustadt stellte er „Leitsätze für Besserung im Bauwesen“ vor und hielt unter anderem „10 Gebote“ für den Bau von Wohnhäusern fest, wovon eines lautete: „Du hast nicht aus dem Rahmen des Ganzen herauszufallen, sondern dich einzugliedern. “75

Im Allgemeinen wurde von der Architektenschaft vor allem an der kompromisslosen Durchführung der Regulierungsvorhaben und an der technokratischen Umsetzung der neuen Baulinien gemäß dem Generalregulierungsplan, der keinen Spielraum für städtebaulich-künstlerische und architektonisch ansprechende, individuelle Lösungen lasse, Kritik geübt.

\subsubsection{Die Positionen der Lehre}

Mit Fragen der Erhaltung der Altstadt und deren „Gesundung“ befasste man sich auch an den Lehrstühlen für Wohnbau, Städtebau und Siedlungswesen ${ }^{\mathbf{7 6}}$ an der Technischen Hochschule und am Lehrstuhl für Kunstgeschichte der Universität Wien.

Als prägende Persönlichkeiten treten an der Technischen Hochschule in den Jahren des Ständestaats vor allem Karl Holey und Erwin Ilz in Erscheinung. Hugo Hassinger bezeichnete 1938 die Lehrkanzel für Städtebau als „Wiege des Heimatschutzgedankens“, da man hier den angehenden Architekten eine „heimatpflegerische Baugesinnung “ lehre. ${ }^{77}$ Die universitäre Ausbildung umfasse nicht nur die Gestaltung von „Neubauten im Kerne der Stadt [...] im Sinne der Heimatpflege“, sondern auch die Frage, wie die für die Gesundung der Bevölkerung als notwendig erachtete Auflockerung der Großstädte durchgeführt werden könne und letztlich wie „alte Stadtkerne assaniert und den wachsenden Verkehrsbedürfnissen angepasst werden [könnten], ohne wertvolles Altes zu zerstören“" ${ }^{\mathbf{8}}$ In den Planungen und Neubauten sollte auf den historischen Bestand weitestgehend Rücksicht genommen, aber dennoch „zeitgemäße“ Lösungen und eine kontrollierte Erneuerung der Stadt zugelassen werden.

Karl Holey $\mathbf{7 9}^{\mathbf{9}}$ hielt in den Jahren des Ständestaats am Institut für „Wohnbau, Städtebau und Siedlungswesen“ Vorlesungen zur Denkmalkunde und zur „Geschichte des Städtebaus “80 und trat durch Vorträge und Stellungnahmen in Tageszeitungen wiederholt in Erscheinung. 1937 wirkte er an der Ausstellung Italiens Stadtbaukunst. Urbanistica Italiana in Regime Fascista mit, die von November bis Dezember des Jahres in den Räumen der Secession gezeigt wurde. Dies alles lässt auf seine fachliche Präsenz und seine Einflussnahme auf Fragen der Stadtplanung schließen. Einen denkmalfachlichen Zugang erwarb er sich nicht zuletzt durch seine langjährige Tätigkeit als technischer Generalkonservator der Zentralkommission für Kunst und historische Denkmale, der späteren Zentralstelle für Denkmalschutz. ${ }^{\mathbf{8 1}}$

Als Vertreter der Heimatschutzbewegung befürwortete er die ganzheitliche Erhaltung von Altstadtensembles und erkannte die Bedeutung der umgebenden, mitunter auch bescheidenen Bauten für die Wirkung der ausgewiesenen Denkmale. Im Sinne 


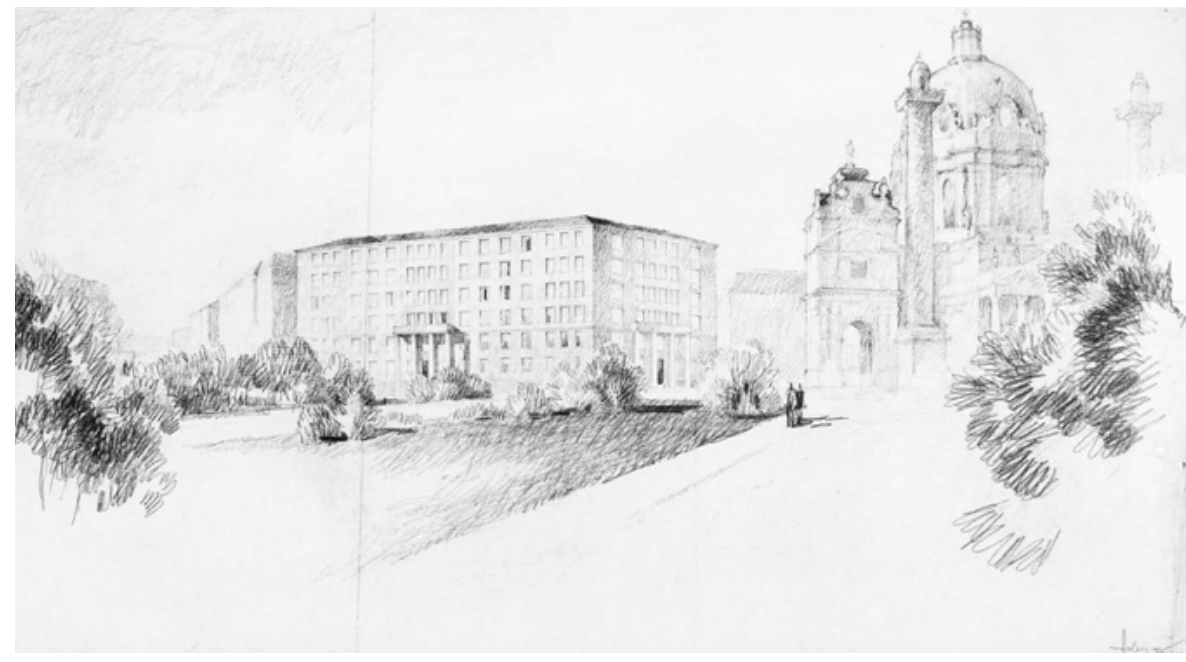

Abb. 89 Karl Holey, Entwurfszeichnung für einen Neubau neben der Karlskirche, nicht ausgeführt, Mai 1936

von Riegls Alterswert könne auch die Schönheit einer Stadt, die „künstlerische Gesamtwirkung“, vom Laien nachempfunden werden. ${ }^{\mathbf{8 2}}$ Die zeitgenössische Architektur sah er als Ergänzung zum Bestand und als Bereicherung, wie er am Beispiel Rom ausführt:

„Ein neues Rom entsteht seit der Machtergreifung des neuen Staatswesens und doch ist und bleibt es das alte, ewige Rom. Das ist das Geheimnis der ewigen Stadt, daß sie sich immer wieder von innen heraus erneuert und verjüngt. Das Neue wird nicht zusammenhanglos an das Alte gefügt oder wie eine neue Schale um einen alten Kern gelegt, der vom Neuen erdrückt oder erstickt würde und abstirbt, nein, das Neue durchdringt das Alte, vermählt sich mit ihm und erfüllt es mit neuem Leben." ${ }^{83}$

Mit dieser Auffassung galt Holey als „objektiv“ und als Vermittler zwischen den Positionen der Stadterneuerung und Stadterhaltung. ${ }^{\mathbf{8 4}}$ Seine Entwürfe für einen Neubau östlich der Karlskirche verdeutlichen, dass er für diesen sensiblen Bauplatz nicht den architektonischen Kontrast suchte, sondern eine eigenständige, aber zurückhaltende Architektur vorzog, eben als bescheidene Ergänzung zum Bestand (Abb. 89) - wie auch in der Lehre vermittelt wurde. Holey bekannte sich zum Ständestaat, der, wie auch andere „Staaten mit starker Führung“, „einen günstigen Boden für ein einheitliches, planvolles Bauen“ biete. ${ }^{85}$ Beleg für seine Nähe zur Politik ist auch der Direktauftrag an ihn für die Planung des österreichischen Kulturinstituts in Rom. ${ }^{\mathbf{8 6}}$ Als großes Beispiel im „planvollen Bauen“ war seiner Meinung nach Italien vorausgegangen, wo ein „verjüngtes Staatswesen unter machtvoller Führung seinen Lebenswillen in einer großen Bautätigkeit“ zur Geltung bringe. ${ }^{\mathbf{8 7}}$ Als erstrebenswert erachtete er eine „Erneuerung von innen heraus“ bei gleichzeitiger Erhaltung der „wertvollen alten Elemente“ und mit dem Ziel, die „neuen Umbildungen“ mit dem Bestand in Beziehung zu bringen, um „die große Einheit“ zu bewahren. Die Erschließung der Altstadt Roms mit neuen Verkehrsadern rücke das alte Rom „erst in das rechte Licht“ und erzeuge eine städtebauliche Eingliederung. ${ }^{\mathbf{8 8}}$ In diesen Bemerkungen wird eine Haltung deutlich, 
die zwischen der Forderung der Erhaltung des wertvollen Alten und der Bewunderung für durchaus radikale städtebauliche und gestalterische Maßnahmen pendelt.

Holey meldete sich auch in viel beachteten Vorträgen zu Wort. Eine tatsächliche Gefahr erkannte er nicht in den Forderungen des Verkehrs, sondern vielmehr in den veränderten Wohnbedürfnissen. Viele Eingriffe in die Altstadt hätten auch taktvoll stattgefunden und zu Recht manches Opfer gefordert. Zu unterbinden war seiner Auffassung nach die unsachgemäße Assanierung und die leichtfertige Zerstörung. Etwas zu optimistisch befand er, dass man gerade in Wien über die gesetzlichen und institutionellen Voraussetzungen verfüge, um das Stadtbild ,in schonungsvollster und künstlerischester [sic!] Weise umzugestalten“.89 Sein Entwurf für einen Assanierungsbau in der Wollzeile zeigt, wie auch der zuvor gezeigte Entwurf für ein Gebäude neben der Karlskirche, ebendiese zurückhaltende, „schonungsvolle“ Einbindung des Neubaus in eine historische Umgebung (Abb. 90), erzielt durch die angeglichene Gebäudehöhe und das Verhältnis von Fenster- und Wandfläche.

Am selben Lehrstuhl hielt Erwin Ilz zwischen 1934 und $1938^{90}$ die Vorlesung „Wohnbau, Städtebau und Siedlungswesen“.91 Karl Giannoni, der im folgenden Kapitel selbst noch im Fokus stehen wird, bezeichnete ihn zwar als besonders geeignet, „Wege des Ausgleiches zwischen den kulturellen Forderungen und jenen des Verkehres zu finden“92, seine Haltung im Umgang mit der historischen Stadt erscheint jedoch durchaus

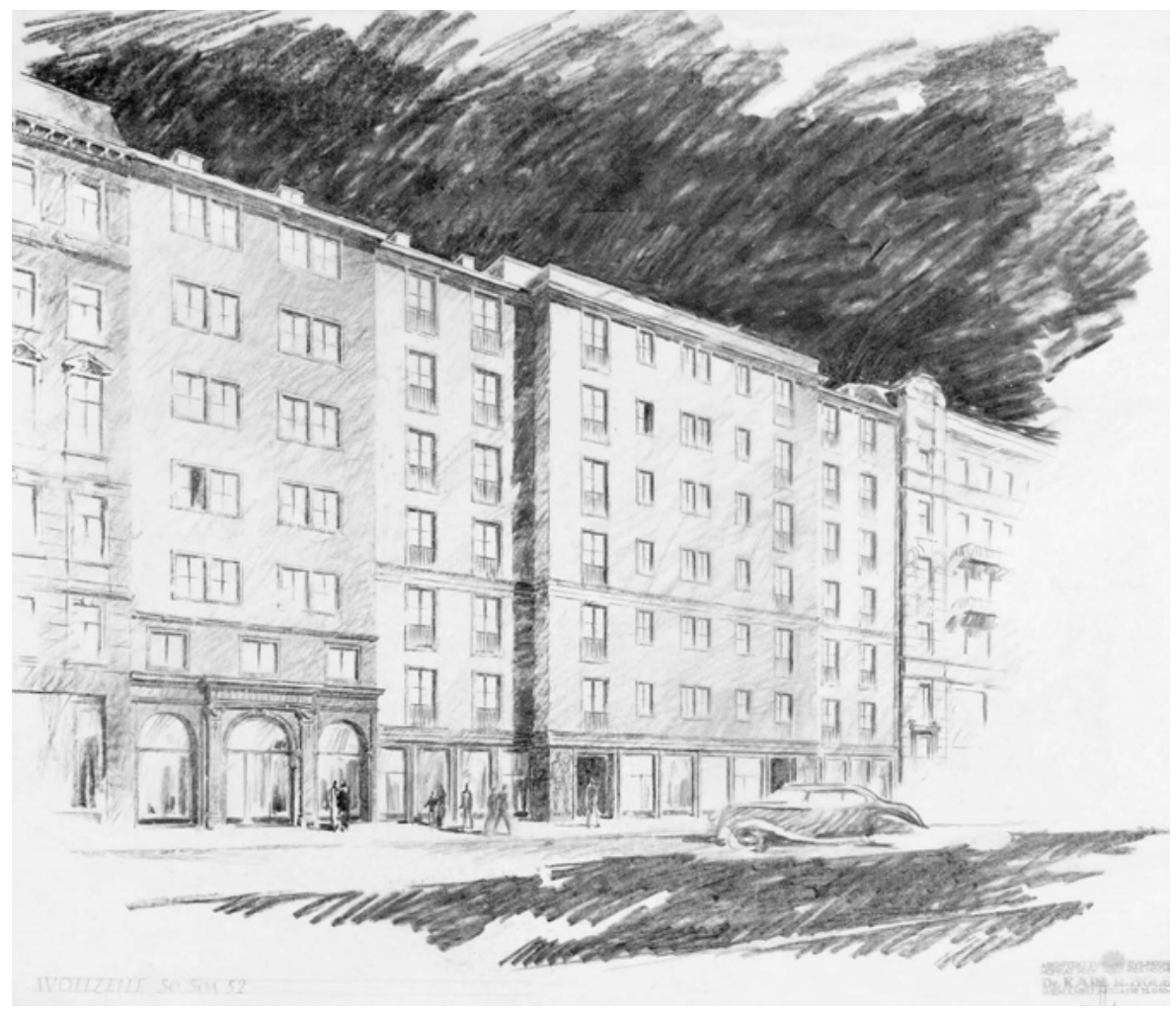

Abb. 90 Karl Holey, Studie für einen Assanierungsbau in der Wollzeile (50,50A und 52), nicht ausgeführt, April 1938 
ambivalent. Ilz verstand unter den „Neuen Aufgaben des Städtebaus“ auch die „Auflockerung der Großstadt [durch eine] Verringerung der Siedlungs- und Wohndichte“ sowie die Schaffung von Freiflächen zur „Entlüftung [...] des überlasteten Großstadtraumes“.93 Darüber hinaus forderte er die große stadtplanerische Geste, sprach sich für weitreichende und durchdachte stadtplanerische Lösungen aus, wie sie Camillo Sitte schon gefordert hatte, anstatt für kleinteilige Maßnahmen und ebenso unbefriedigende Kompromisslösungen. Die „Ordnung der Verkehrsfragen“, mit Blick auf die „großen Zusammenhänge“, bildete seiner Ansicht nach die Grundlage jeder baukünstlerischen Lösung. ${ }^{94}$ Die zeitgenössische Architektur müsse dabei auch neuartig gestaltet werden. Ziel sei es, „aus dem heutigen Leben eine selbständige Form“ zu entwickeln und nicht „Vergangenem, dem unwiederbringlich Zerstörten“ nachzutrauern. ${ }^{95}$ Diese progressive Auffassung von Architektur und sein mitunter radikaler Ansatz fanden sich dennoch in den Interessen der Heimatschutzbewegung wieder, belegt auch durch seine Mitgliedschaft im Österreichischen Verband für Heimatpflege. ${ }^{96}$

Ilz befasste sich intensiv mit der Frage der Altstadtsanierung, mit den damaligen und möglichen Methoden der Assanierung, wie der Auskernung verbauter Hofflächen, Straßendurchbrüchen und der „Niederlegung“ ganzer Stadtviertel, und war auch für radikale Lösungen offen. Seiner Meinung nach dränge die Gesellschaft nun dazu, der „geänderten Geistesrichtung“ auch in den Städten „monumentalen Ausdruck zu verleihen“.97 Ebenso wie Holey kritisierte er den Städtebau des 19. Jahrhunderts, vor allem die kurzsichtige Maßnahme der Straßenverbreiterung durch Zurückversetzung der Baulinien. Seiner Ansicht nach gebe es mehrere Methoden, in Kombination und „nach einem einheitlichen Plan“ eingesetzt, die die Erhaltung von „Alt-Wien“ ermöglichen könnten: Die bereits genannte Auskernung von Hofflächen, „unter Schonung künstlerisch wertvoller Teile“, die Entkernung, die es ermögliche, die historischen Schauseiten zu erhalten und dahinter Neubauten zu errichten, „die allen Anforderungen der Technik und Hygiene von heute“ entsprächen. Zuletzt seien in Bereichen der Stadt, „wo keine Schonung vonnöten“ sei, die Anlage „moderner neuer Straßenzüge“ angebracht. Auch eine „Durchtunnelung“ von Bestandsbauten (anstelle von Straßendurchbrüchen) sei denkbar, um eine weitgehende Erhaltung zu ermöglichen. Gerade die Entkernung historisch wertvoller Gebäude sah er als international erprobtes Mittel, das auch den Forderungen des Denkmalschutzes nachkomme.98

Am Lehrstuhl für Kunstgeschichte an der Universität Wien war in erster Linie Hans Sedlmayr ${ }^{\mathbf{9}}$ mit Aspekten des Städtebaus und der Altstadterhaltung befasst. In seinem Engagement für die Erhaltung historischer Stadtbilder folgte er seinem „unvergesslichen Lehrer Max Dvořák“, dessen Lehrstuhl er 1936 von Julius Schlosser übernommen hatte. ${ }^{\mathbf{1 0 0}}$ Auch Sedlmayr kritisierte den bestehenden Generalregulierungsplan, der das historische Wien vernichten und zugleich auch „ein wirklich modernes Wien“ verhindern würde. ${ }^{\mathbf{1 0 1}}$ Um dem zunehmenden Verlust von „Alt-Wien“ entgegenzuwirken, sammelte er im Jänner 1938 gemeinsam mit seinem Assistenten Karl Oettinger 30.000 Unterschriften gegen den Abbruch des Palais Paar in der Wollzeile, worauf wir noch zurückkommen werden. ${ }^{\mathbf{1 0 2}}$

Seiner Ansicht nach konnten dem Verkehr gewisse Opfer gebracht werden, allerdings nur, wenn „ein klares Ziel“ feststehe. ${ }^{103}$ Städtebauliche Lösungen sollten aus der Eigenart der jeweiligen Stadt und ihrer Geschichte heraus entwickelt werden, im 
großen wie im kleinen Maßstab. Für Wien plante er im Jahr 1939 einen neuen Stadtkern im 2. Bezirk, um dadurch die Altstadt innerhalb der Ringstraße zur Gänze erhalten zu können. ${ }^{\mathbf{1 0 4}}$ Auf ideologische Hintergründe soll hier nicht näher eingegangen werden, allerdings planten auch Architekten und Stadtplaner im Auftrag der Nationalsozialisten eine Monumentalachse durch den 2. und 20. Bezirk sowie ein Forum jenseits der Donau. ${ }^{105}$ Bezeichnend ist, dass auch für Sedlmayr die jüdisch geprägte Altstadt im Bereich des 2. Bezirks durchaus geopfert werden konnte.

Seine gemeinsam mit Oettinger verfassten Beiträge zur Denkmalpflege wollte er 1940 publizieren, „als Beweis, dass auch seit 1936 der Geist Riegls und Dvořáks am Institut lebendig geblieben“106 sei - wohl auch eine Anspielung auf die kritische Haltung des Lehrstuhls zur fortschreitenden „Stadterneuerung“. Auch Oettinger erkannte, wie Sedlmayr und Holey, bei allem Erhaltungswillen für die wenigen noch bestehenden „Altstadtinseln [...] in ihrer städtebaulichen Einheit“, die Bedeutung zeitgenössischer Architektur, wenngleich in Abwägung der Argumente nur die wirklich notwendigen Demolierungen erfolgen sollten. ${ }^{\mathbf{1 0 7}}$

Mit Fragen der Stadtgestaltung und Stadtbildpflege waren an der Universität Wien jedoch nicht nur Kunsthistoriker befasst. Auch der Kulturgeograph Hugo Hassinger, der bereits im Zusammenhang mit der Begründung der Heimatschutzbewegung und der städtebaulichen Denkmalpflege im frühen 20. Jahrhundert mehrfach erwähnt wurde, war auf diesem Gebiet tätig. Hassinger hatte 1931 die Lehrkanzel für Kulturgeographie übernommen, die er bis 1951 leitete. ${ }^{108}$ Für den 15. Band der Österreichischen Kunsttopographie hatte er noch vor dem Ersten Weltkrieg die bereits mehrfach gezeigten kunsthistorischen Pläne erstellt, die den Denkmalbestand in Wien eindrücklich darstellen und vor allem zusammenhängende Ensembles auf bisher unbekannte Weise veranschaulichten. Er vertrat ebenfalls den Standpunkt des Heimatschutzes, der seiner Ansicht nach eben „kein Hemmnis des Fortschrittes, sondern im Gegenteil kulturelle Aufbauarbeit und Weiterentwicklung“ bedeute. In Wien sah er aufgrund der vorhandenen Denkmalschutzgesetzgebung, des seit der Jahrhundertwende aufstrebenden Heimatschutzgedankens und der zahlreichen, bereits erschienenen Schriften zum Thema der Altstadterhaltung beste Voraussetzungen für „eine im Sinne des Heimatschutzes sich vollziehende Umbildung“ der Stadt gegeben. ${ }^{109}$

\subsubsection{Die Stimme des Heimatschutzes}

Die Heimatschutzbewegung übte schon kurz nach 1900 harsche Kritik an der radikalen Stadterneuerung. In den 1930er-Jahren führte der Österreichische Verband für Heimatpflege ${ }^{\mathbf{1 1 0}}$ diesen Kampf fort. Die jährlich stattfindenden Tagungen dienten dem fachlichen Austausch und der Diskussion aktueller Themen, wobei der Ortsbildschutz mehrfach eine zentrale Rolle spielte.111

Für den Kunsthistoriker Hans Tietze war die „alte Denkmalpflege“ eine wissenschaftliche Disziplin, die Heimatschutzbewegung hingegen eine „sittliche Forderung“, eine neue Weltanschauung mit einer "täglich wachsenden Schar" an Anhängern.112 Eine ähnliche Anschauung vertrat Max Dvořák, der im Gegensatz zur Denkmalpflege, als Ausdruck eines gebildeten kleinen Kreises, den Heimatschutz als ein Phänomen verstand, das die gesamte Bevölkerung erfassen sollte und auch konnte. ${ }^{\mathbf{1 1 3}}$ Auch in den 1930er-Jahren bestanden große Übereinstimmungen mit den Agenden der Zentralstelle für Denkmalschutz. Dies schlug sich auch in den Personalien nieder: 
Leiter der 1923 eingerichteten Fachstelle für Fragen des Natur- und Heimatschutzes in der Zentralstelle war Karl Giannoni144, der ab den 1920er-Jahren auch Vorsitzender des Österreichischen Verbandes für Heimatpflege war.115 Der Fachausschuss des Vereins setzte sich aus einigen der damals wichtigsten Experten im Bereich des Städtebaus und der Denkmalpflege zusammen. Zu den prägenden Mitgliedern zählten neben Giannoni, Holey und Oskar Oberwalder (Zentralstelle) ab 1934 auch Hugo Hassinger, Erwin Ilz und Robert Oerley, deren Position im Diskurs zur Stadterneuerung vorhin erläutert wurde. ${ }^{\mathbf{1 1 6}} \mathrm{Im}$ Verein waren also gleichermaßen Stadtplaner, Architekten wie Kunsthistoriker vertreten, die sich im gemeinsamen Diskurs mit Fragen der Stadterhaltung befassten.

Der Verband bemühte sich durch die Veranstaltung einer Wanderausstellung zum Thema Heimatpflege, die seit den 1920er-Jahren in zahlreichen Gemeinden Station machte und von erläuternden Vorträgen begleitet wurde, um die Verbreitung der Anliegen der Denkmalpflege und des Ortsbildschutzes. ${ }^{\mathbf{1 1 7}}$ In Deutschland zeigte man sich tief beeindruckt von der Arbeit des Verbandes. ${ }^{\mathbf{1 1 8}}$ Die Verbindung des staatlichen und vereinsmäßigen Heimatschutzes in Personalunion durch Karl Giannoni, die auch in den Bundesländern durch die oftmalige ehrenamtliche Tätigkeit der Landeskonservatoren als Vorsitzende der Länderorganisationen des Heimatschutzes gegeben war, betrachtete man als gute Voraussetzung, um „tiefer in die Bevölkerung einzuwirken[,] als dies rein amtlich gelingen würde“.119

Der „Heimatsinn“ sollte laut Giannoni die ganze Bevölkerung erfassen, um in Zukunft die Erhaltung der Ortsbilder bei einer gleichzeitigen Weiterentwicklung der „ortstypischen“ Bauweise zu gewährleisten.120 Er sah für Wien eine „Umbildung im Sinne des Heimatschutzes“ vor und wollte die Suche nach einem neuen „Heimatstil“, einer neuen „heimatlichen Bauweise“ vorantreiben.121 Bei „einer notwendigen Auswechslung alter Teile durch neue“ sollte jedoch die Gesamtwirkung nicht zerstört werden,122 ein Abwägen also zwischen der Berechtigung des bestehenden „Alten“ und dem geplanten „Neuen“, das die Heimatschutzbewegung schon in ihren Anfängen kurz nach 1900 gefordert hatte. Das „Neue“ sollte sich dem Gesamtbild der Straße unterordnen und anpassen. Als besten Schutz für die Erhaltung der Altstadt erachtete der Heimatschutz die „Verkehrsablenkung“ und die „Gründung von dezentralisierenden Neustadtteilen".123

Die in den Anfängen der Bewegung noch vorhandene, aufgeschlossene Haltung gegenüber der zeitgenössischen Architektur, während man historistische Architektur vor allem im Wohnbau ablehnte, verflog im Laufe der 1920er-Jahre, bis man schließlich in den 1930er-Jahren in eine „Überbetonung des ,Heimat-Begriffs““ und in „,ölkischnationale“ Leitgedanken abdriftete. ${ }^{\mathbf{1 2 4}}$ Diese Entwicklung zeigt auch die zuvor erwähnte Wanderausstellung des Verbandes für Heimatpflege, die von 1920 bis 1940 unter wechselndem Titel ${ }^{\mathbf{1 2 5}}$ in zahlreichen Städten Österreichs gezeigt wurde. Die Ausstellung wurde mehrfach überarbeitet und ergänzt und in den gezeigten Fotografien auch an die jeweiligen Ausstellungsorte angepasst. In der Gegenüberstellung von guten und schlechten Beispielen, „störende Gegenbeispiele späterer Zeit und [...] vorbildliche Beispiele neuesten Schaffens“126 (Abb. 91), sollte das Bewusstsein für Gestaltungsfragen geweckt und die kommende Entwicklung der Dörfer und Städte beeinflusst werden. 


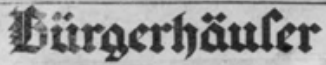

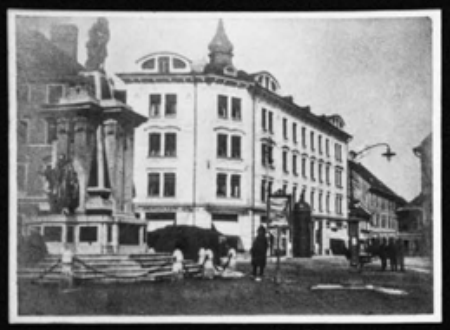

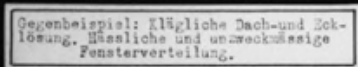
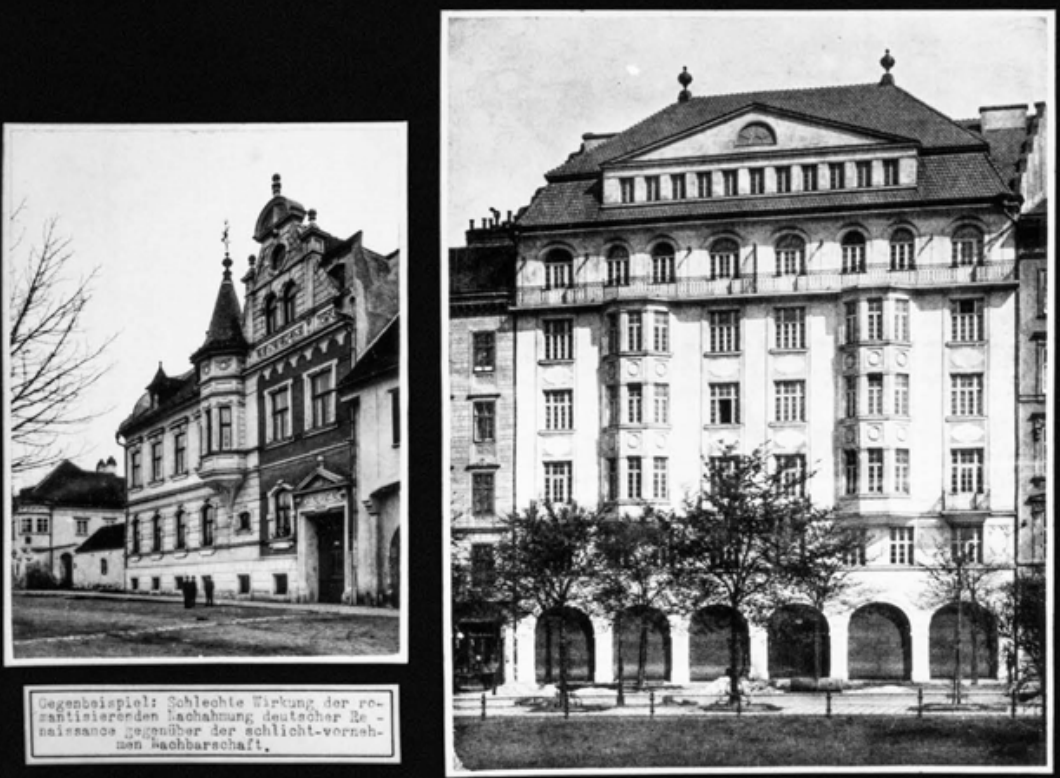

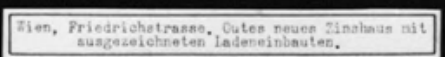
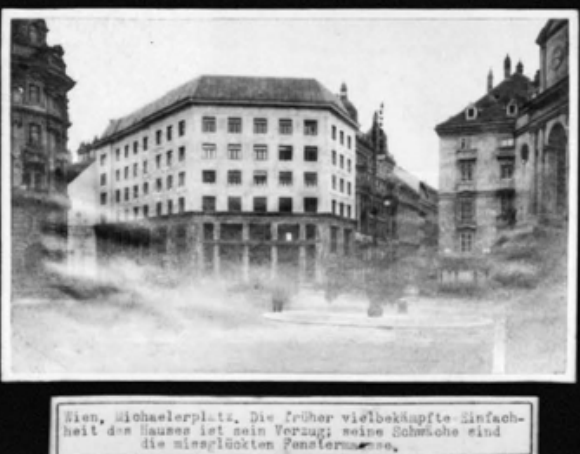
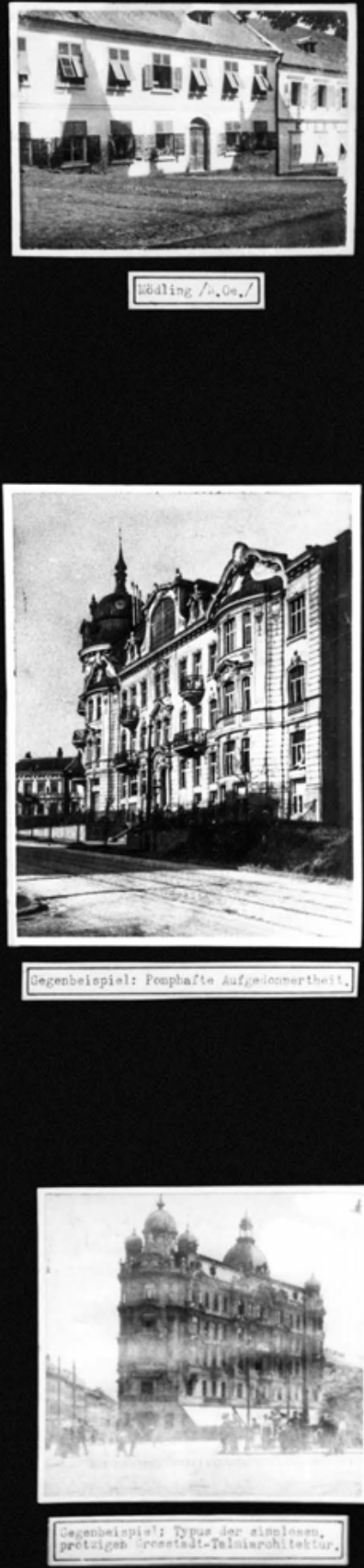


\section{Buts 犺subatem.}

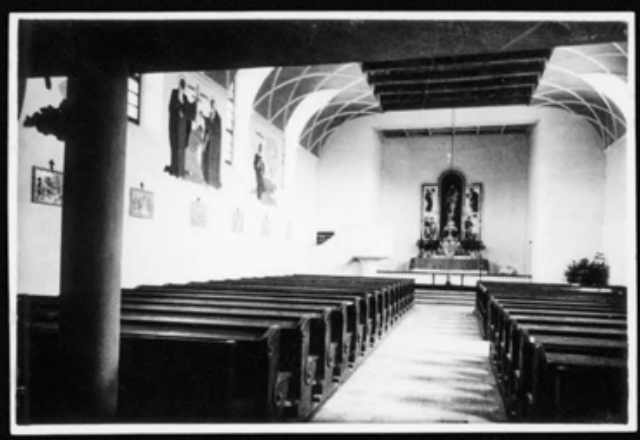

Outtentach.tious zirche.

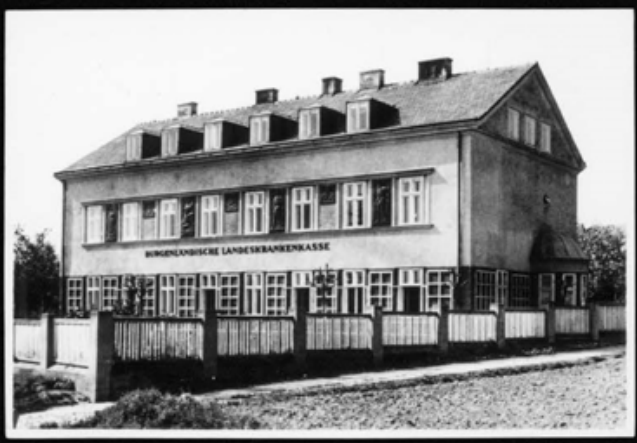

Sauerirunn. Landeckrankerkaree.
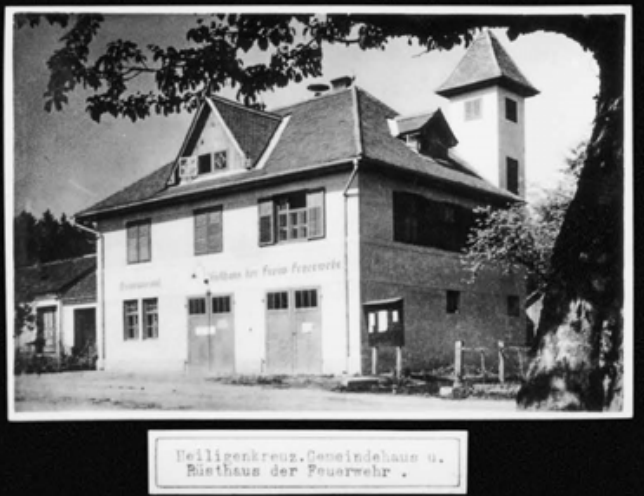

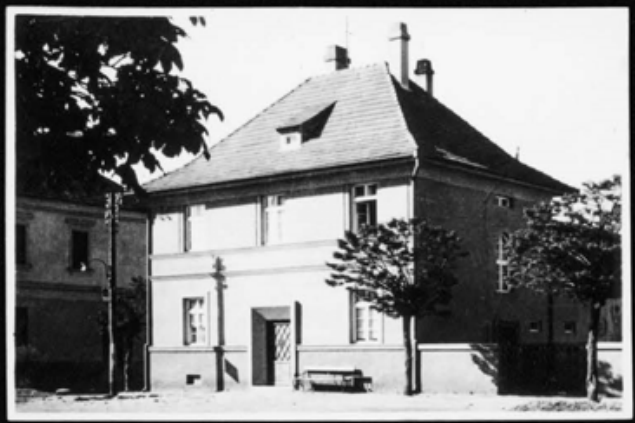

Grose Petersiorfonfarriof.

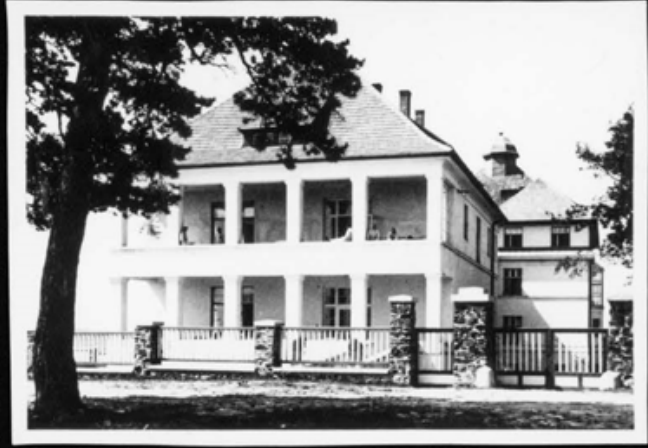

Cberpullericret.kmankentans.
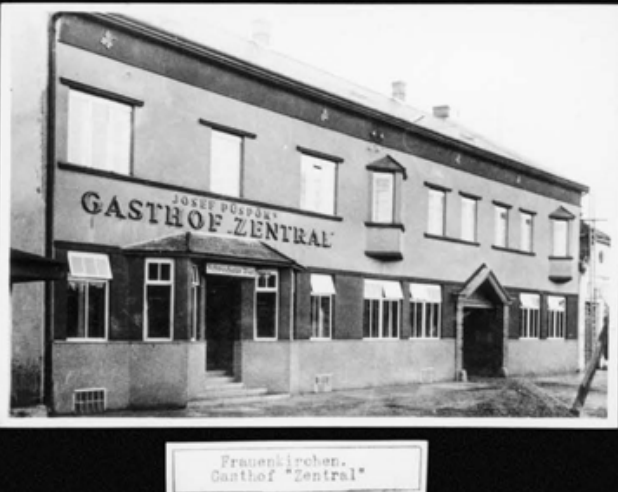
„Werte der Heimat, die in Landschaft und Ortschaft sichtbar sind, will die Ausstellung in Beispielen darstellen. In Gegenbeispielen will sie zeigen, wie solche Werte zum Schaden der Allgemeinheit vernichtet oder beeinträchtigt werden durch Gleichgültigkeit, rücksichtslose Gewinnsucht od. den Unverstand unzulänglichen Könnens. Und wieder an guten Beispielen neuester Zeit soll deutlich werden, daß diese gelernt hat, das wirtschaftlich Notwendige mit dem sozial Guten und dem künstlerisch Schönen zu vereinigen. Sehen lehren will die Ausstellung und gegenüber gutem Bestehendem zu Ehrfurcht vor der Vergangenheit führen, gegenüber dem Neuschaffen aber, das dem Alten nicht gleichartig aber gleichwertig sein soll, zum Verantwortungsbewusstsein vor der Zukunft."127

Als „gut“ befand man die „ruhige Wirkung“128 der teils klassizierenden, teils biedermeierlichen bis heimattümelnden Architektursprache. Begrüßt wurde eine „ruhige Monumentalität“, klare Formen und Kubaturen, stets mit besonderer Bedachtnahme auf die Größenverhältnisse sowie Struktur und Vokabular der umgebenden Bebauung. Zurückhaltende, unaufdringliche Bauten, versehen mit (teils abstrahierten) Zitaten der regionalen Bauweise (Satteldächer, Gaupen, Fensterläden, Arkaden), waren gern gesehen und wurden nicht als bestimmende, sondern als ergänzende Elemente zu historischen Straßen- und Platzbildern verstanden (Abb. 92). Kritisiert wurde in den Bildunterschriften der ausgestellten Fotoaufnahmen vor allem die „billige Monumentalität“ oder „pomphafte Aufgedonnertheit“ der Architektur des Historismus, ihre „Bauspielerei“ mit Motiven und der „Typus der sinnlosen, protzigen Grosstadt-Talmiarchitektur [sic!]“ im Allgemeinen. Für die Tabakfabrik in Linz von Alexander Popp und das Haus am Michaelerplatz von Adolf Loos fand man hingegen durchaus lobende Worte. Der Vorzug des zuletzt Genannten liege in der „Einfachheit“ der Gestaltung. ${ }^{\mathbf{2 2 9}}$ In Fortsetzung der Bestrebungen der frühen Heimatschutzbewegung übte man also auch in den 1930er-Jahren harsche Kritik an Städtebau und Architektur der Gründerzeit, was damals allgemein denkmalpflegerischer Tenor war (über die Landesgrenzen hinaus) und zugleich die denkmalpflegerische Praxis dieser Jahre beeinflusste, und befasste sich auch intensiv mit der jüngeren und zeitgenössischen Architektur.

Den Beschluss der Stadtverwaltung, eine Kommission zur Klärung der Regulierungs- und Assanierungsfragen zu gründen, begrüßte man auch in den Reihen des Heimatschutzes. Eine für November 1937 geplante „Protestversammlung gegen den Demolierungsplan der Inneren Stadt“ wurde schließlich abgesagt, da man selbst in die Kommission miteingebunden werden wollte. ${ }^{\mathbf{1 3 0}}$ Stattdessen sandte man im Jänner 1938, im Zusammenschluss mit anderen Vereinigungen ${ }^{\mathbf{1 3 1}}$, ein Memorandum mit Leitgedanken zum Städtebau an den Bürgermeister. ${ }^{\mathbf{1 3 2}}$ Weite Passagen dieser Denkschrift wurden von Hans Sedlmayr und Robert Oerley verfasst. ${ }^{\mathbf{1 3 3}}$ Gefordert wurde darin etwa die Aufnahme von Vertretern des Heimatschutzes in die Kommission, wie die Universitätsprofessoren Erwin Ilz oder Hugo Hassinger, der sich „schon vor dem Kriege [...] für einen verstärkten Schutz des alten Wien ausgesprochen und gegen die Gefahren, die es damals wie heute bedrohten“, gewendet habe. ${ }^{\mathbf{1 3 4}}$ Man forderte den Schutz der Stadt Wien „als Ganzes“ und damit die Erhaltung der Eigenart und des Charakters. Geschützt werden sollten die Altstadtbereiche der inneren Bezirke (II-IX), aber - ganz im Sinne Max Dvořáks - auch die „reizenden Ortsbilder in den alten Siedlungskernen der äußeren Bezirke“, die durch das Wachstum der Großstadt bedroht waren. Betont 
wird in der Denkschrift auch die Bedeutung der Umgebung von Denkmalen. Nicht nur die „überragende[n] Werke der Kunst“, auch bescheidene Objekte, „das scheinbar Geringe“, seien für die Identität der Wiener Bevölkerung und das charakteristische Stadtbild bedeutsam. ${ }^{135}$

\subsubsection{Reaktionen der Öffentlichkeit}

Über das „Neue Wien“ und seine Bauten berichteten auch die Tageszeitungen - und das nicht nur in Wien, sondern auch in den Bundesländern. ${ }^{\mathbf{1 3 6}}$ In den Jahren 1934 und 1935 ist eine starke Befürwortung der Assanierungsaktion festzustellen, während ab Mitte der 1930er-Jahre die Kritik der Bevölkerung und der Medien an den Regulierungsplänen der Stadtverwaltung zunimmt und schließlich Ende des Jahres 1937 ein heftiger Protest einsetzt.

In den Anfangsjahren der Assanierung werden in den Tageszeitungen noch die positiven Aspekte des Aufbauprogrammes, wie die verkehrstechnischen Verbesserungen, unterstrichen:

„[...] wenn man es einmal eilig hat, etwa im Auto rasch an sein Ziel zu kommen, dann merkt man [...] wie sehr es an der Zeit ist, unter möglichster Schonung der Geschichte und Tradition dieser Stadt die Verkehrshindernisse zu entfernen und wie begrüßenswert dieser erste Schritt der Wiener Gemeindeverwaltung zum Großreinemachen im regellosen Stadtbild ist." ${ }^{\mathbf{1 3 7}}$

Vor allem „regierungstreue“ Medien wie die Reichspost begrüßen im Jahr 1934, dass die notwendige Regulierung der Inneren Stadt und der ehemaligen Vorstädte von der neuen politischen Führung nun „endlich“ in Angriff genommen werde. ${ }^{\mathbf{1 3 8}}$ Gleichzeitig wird die „einseitige politische Einstellung der sozialdemokratischen Stadtverwaltung“ kritisiert, die eine weitere „Modernisierung“ der Wiener Altstadt nach dem Ersten Weltkrieg vernachlässigt habe. ${ }^{\mathbf{1 3 9}}$ Statt die dringlichen verkehrstechnischen und städtebaulichen Fragen der Innenstadt zu lösen, habe sich die Gemeinde fast ausschließlich auf den Bau von Großwohnanlagen an der Peripherie konzentriert. Als Konsequenz gäbe es „heute kaum mehr eine europäische Großstadt, die ein so uneinheitliches und unlogisches städtebauliches Bild“ aufweise wie Wien. ${ }^{\mathbf{1 4 0}}$

Mit vergleichbarer Euphorie schreibt die unter Beeinflussung stehende Neue Freie Presse (siehe dazu auch Kap. 2.3) im Jahr 1936 über die Initiative der neuen Stadtregierung in Sachen Arbeitsbeschaffung und Altstadtregulierung:

„Mit nicht genug anzuerkennender Energie wird an der Erneuerung Wiens gearbeitet. Die Bevölkerung weiß dem Bürgermeister aufrichtigen Dank dafür, daß das kommunale Arbeitsprogramm wahrlich nicht auf dem Papier stehen bleibt, daß Straßenbauten im ganzen Stadtgebiet durchgeführt werden, daß zahlreiche Arbeitslose Brot und Erwerb finden, daß Engpässe verschwinden, Verkehrshindernisse beseitigt werden, daß sich allüberall fleißige Hände rühren. [...] Nach einem weitausgreifenden Plan geschieht unendlich viel sowohl für die Verschönerung als auch für die Assanierung Wiens, für die Ausgestaltung der Verkehrswege, für Erleichterung und Förderung von Handel und Wandel.“141 
Der bereits von Dvořák konstatierte „Fortschrittswahn“, hier ins Positive gekehrt als Forderung der Zeit und des modernen Städtebaus, geht ebenso deutlich aus der tendenziösen Berichterstattung im Neuen Wiener Journal hervor:

„Und was hat es für Kämpfe gekostet, bis die Risalite und Erker und Balkone und sonstigen schönen, aber unpraktischen Mauervorsprünge, die das historische Stadtbild herstellten, wegrasiert werden durften. Altes zu ehren, ist ein schöner Grundsatz des bodenständigen Wienertums, doch Neuem nicht zu wehren ist eine unabweisliche Forderung der Zeit, die mit ihrem Entwicklungstempo nicht vor Riesennippes [Nippes = Ziergegenstände aus Porzellan, Anm. d. Autorin] haltmachen kann.“"142

Auch Architekturzeitschriften, wie der Österreichische Baumeister, äußerten naturgemäß Interesse an der baulichen Umgestaltung und drängten darauf, „den Verkehr störende Häuser zu beseitigen und durch Neubauten zu ersetzen“. Darüber hinaus sollten auch die als minderwertig erachteten „Mietskasernen“ der Gründerzeit mit ihren Hof- und Seitentrakten „gesunden“ Wohnbauten weichen. ${ }^{\mathbf{1 4 3}}$ Ausgiebig und zumeist äußerst euphorisch reagierten die Fachzeitschriften auf die Gestaltung der Assanierungsbauten - unter Schlagzeilen wie beispielsweise „Die Straße frei der neuen Zeit“.144 Schlagworte wie „modern“, „gediegen“, „hygienisch“, „sauber“ und „gesund“ bestimmen die Beschreibungen. Nicht nur das äußere Erscheinungsbild entsprach dank der

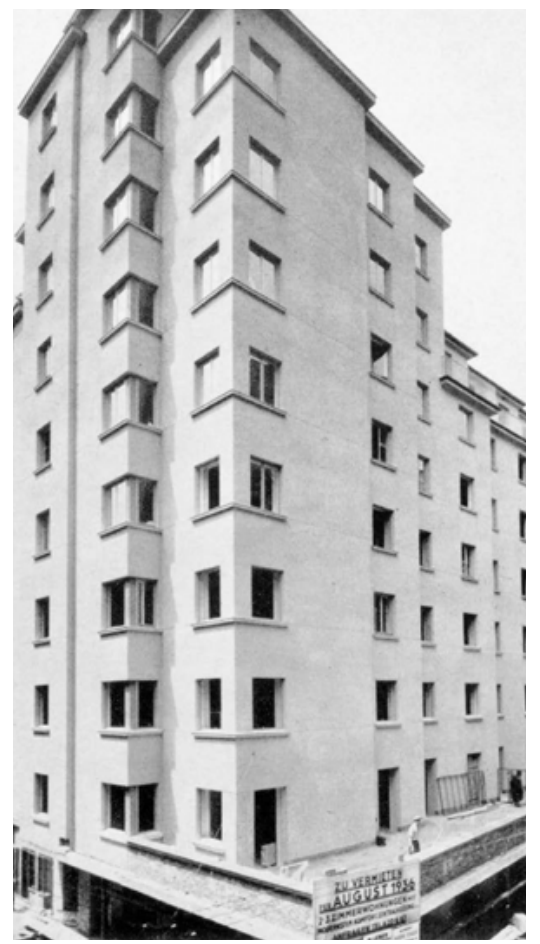

Abb. 93 Angelo Felix Pollak, Assanierungsbau am Laurenzerberg vor der Fertigstellung, Aufnahme vermutlich 1936

\section{Ö S T E R R E I C H I S C H E K U N S T}

Carl Wilh. Schmidt: Bauten und Projekte

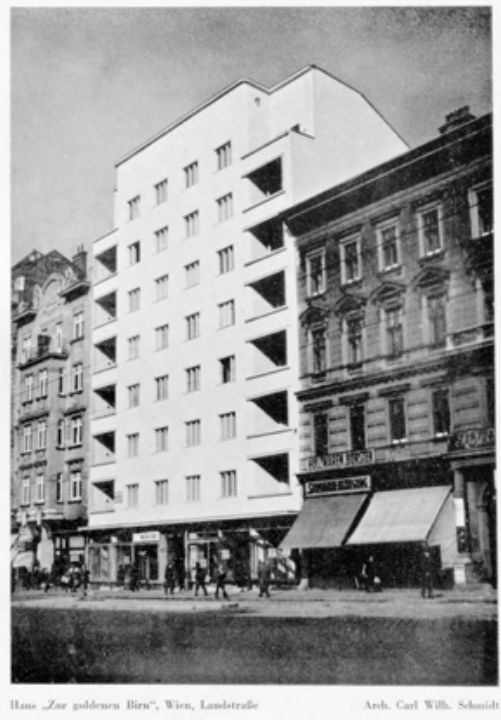

Abb. 94 Carl Wilhelm Schmidt, Assanierungsbau Landstraßer Hauptstraße 31, errichtet 1934/35, Publikation von 1936 


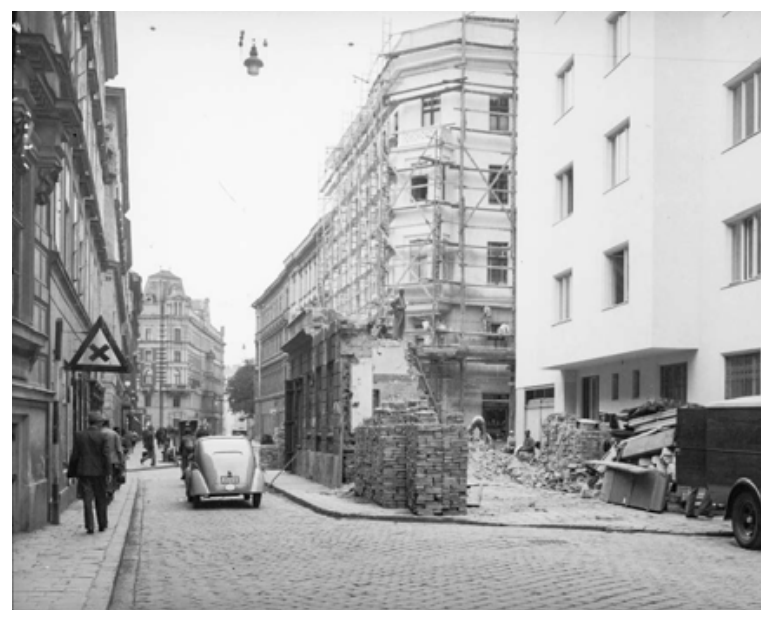

Abb. 95 Assanierungsbau Ecke Reisnerstraße 10 und Beatrixgasse 23; davor sind noch die Reste des dafür abgebrochenen Gebäudes zu sehen, Aufnahme vermutlich 1936 glatten und hellen Putzfassaden diesen Parametern, sondern auch die licht- und luftdurchfluteten Wohnungen. Die „modernste wohntechnische Ausstattung“"145 und der Komfort der Kleinwohnungen werden bei nahezu allen Beschreibungen betont, etwa die Warmwasserversorgung, vorhandene Elektro- bzw. Zentralheizung, die Ausstattung der Küchen mit Elektrogeräten und die Erschließung durch moderne Aufzüge. ${ }^{\mathbf{1 4 6}}$

Zahlreichen Beschreibungen gemein ist das Bedürfnis, die Architektur vom unausgesprochenen Vorwurf der $(\mathrm{zu})$ rigiden Sachlichkeit loszulösen und die architektonischen Qualitäten hervorzuheben.147 Die Assanierungsbauten werden als stadtbildbereichernde Gebäude präsentiert: Jener am Laurenzerberg wird beispielsweise als Neubau von „kühner Modernität“ bezeichnet, der sich steil aus dem verwinkelten alten Straßengewirr erhebe und dank seiner Dachterrassen und „Abstufungen aller Art“ weit entfernt sei von der „langweilige[n] Raumwirkung des Zinshauses der letzten Generation“ (Abb. 93). ${ }^{\mathbf{1 4 8}}$

Zur Verdeutlichung des „sauberen“, „modernen“ Charakters der Assanierungsbauten wird auch Bildmaterial bewusst eingesetzt. So hebt sich in der Schwarz-WeißFotografie des Assanierungsbaus an der Landstraßer Hauptstraße 31 die klare, strahlendweiße Front von den angrenzenden Gebäuden besonders deutlich ab (Abb. 94). Auch die Gegenüberstellung mit den abgetragenen Altbauten wird gesucht, um die vermeintlichen städtebaulichen und „hygienischen“ Verbesserungen und architektonischen Vorzüge zu veranschaulichen (Abb. 95).

Wie sehr sich der Standpunkt der Presse zur Assanierung in den Jahren 1937/38 wandelte, erkennt man an einprägsamen Schlagzeilen wie „Lasst uns noch ein paar alte Gassen...!“149, „Für Erhaltung des alten Wien“150, „Aufruf zur Erhaltung von AltWien“151, „Fünf edle Häuser bitten um Gnade“152 und dergleichen, die vor allem in den späten Jännertagen des Jahres 1938 die Wiener Tageszeitungen bestimmten. Auch regierungstreue Blätter wie die Reichspost nahmen den Unmut aus der Bevölkerung auf und unterstützten die Kritik an der fortschreitenden Abrisstätigkeit. ${ }^{\mathbf{1 5 3}}$ Die Zeitschrift Österreichische Kunst berichtete nun eindringlich über die Gefahren, die dem Wiener Stadtbild drohten und kritisierte die Bauspekulation und den sinnlosen Abbruch historischer Bausubstanz für eine schlechte, unüberlegte Verkehrsplanung. 154

Der Unmut der Wiener Bevölkerung wurde vor allem mit dem Bekanntwerden der geplanten Demolierung des Palais Paar und dem anstehenden Umbau des Dominikanerkonvents unüberhörbar deutlich. Auch der Wettbewerb zur städtebaulichen Umgestaltung des Grinzinger Ortskerns trug seinen Teil dazu bei. Nachdem Regulierungspläne des Stadtbauamtes bekannt geworden waren, waren es laut dem Neuigkeits-Welt-Blatt 
„abertausende Freunde Grinzings“, die sich „geradezu leidenschaftlich für die vollständige Erhaltung der idyllischen Häuserzeilen des alten Hauerortes und seiner Gäßchen“ einsetzten. ${ }^{\mathbf{1 5 5}}$ Schon zu Beginn der 1930er-Jahre erreichten die Zentralstelle Briefe von Privatpersonen, zumeist Nicht-Fachleuten, die ihre Sorge um die Erhaltung des Stadtbildes ausdrückten. Die Zuschriften schätzte man sehr, vor allem Viktor Schneider, seit 1931 Korrespondent der Zentralstelle, ${ }^{\mathbf{1 5 6}}$ dankte man für seinen „mannhaften und unbeirrbaren Einsatz [...] für die Rettung des barocken Wiener Stadtbildes“.157 Die Kritik Schneiders richtete sich in erster Linie an die Investoren und Baufirmen und weniger an die Stadt Wien, wenn er auch die verkehrsbedingte Regulierung hart kritisierte. ${ }^{158}$

„Ich bitte, sie [seine Aufsätze zur Rettung des Wiener Stadtbildes, Anm. d. Autorin] als Hilferuf eines um das Schicksal seiner Wienerstadt ernst besorgten Wieners anzusehen und überzeugt zu sein, daß sie Tausenden meiner Mitbürger und gewiß nicht den schlechtesten aus der Seele gesprochen sind, kaum jemand weiß ich, der mit mir nicht eines Sinnes wäre, aber ich weiß viele, die mir aus ganzem Herzen gedankt haben.“159

Auch aus dem Ausland, vor allem aus Deutschland, erreichten die Zentralstelle zahlreiche Briefe von Privatpersonen, die sich um die bauliche Zukunft Wiens sorgten. ${ }^{\mathbf{1 6 0}}$

„Nürnberg schützt seine alten Viertel, Wien reisst [sic!] sie ruchlos nieder. Ist es nicht möglich, wenigstens die bis auf eine Kleinigkeit gut erhaltene Liechtenthalergasse unter unbedingten Denkmalschutz zu stellen? Wie lieblich ist der Anblick von der Kirche durch die Liechtenthalerstrasse [sic!] zu - der Geist Schuberts weht einem entgegen!“161

Den Höhepunkt erreichte die Protestbewegung mit der von Hans Sedlmayr und Karl Oettinger initiierten Unterschriftenaktion vom Jänner 1938, die gemeinsam mit einer von wichtigen Persönlichkeiten des öffentlichen Lebens unterfertigten „Denkschrift“ am 20. Jänner an den Bundespräsidenten sowie an den Bundeskanzler und den Bürgermeister von Wien erging. ${ }^{\mathbf{1 6 2}}$ Auslöser dafür waren in erster Linie der bevorstehende Abbruch des Palais Paar und vor allem auch die damals noch in Planung begriffenen Demolierungen in der Singerstraße (Nr. 30 und 32). ${ }^{\mathbf{1 6 3}}$ Gemeinsam mit der Unterschriftenaktion versuchte eine Reihe führender Persönlichkeiten des Wiener Kulturlebens gegen die steigende Zahl an Demolierungen zu protestieren, in der Hoffnung, damit „ein geschichtlich und künstlerisch einzigartiges Stadtbild für die Nachwelt zu bewahren“. Als eigentliches Problem identifizierte man auch hier den immer noch als Planungsgrundlage dienenden Generalregulierungsplan des 19. Jahrhunderts, der den „Anschauungen von Denkmalwert und Denkmalschutz“ nicht mehr entspreche und andererseits „die Durchführung der modernen Prinzipien des Städtebaues“ verhindere. ${ }^{164}$

Zahlreiche Berichte in diversen Zeitschriften und Tageszeitungen begrüßten die Unterschriftenaktion. Die Zeitschrift Österreichische Kunst äußerte gar die Hoffnung, dass dadurch das „häufig zu tief schlummernde Interesse des Wieners an den Kunstfragen seiner Heimat" geweckt werde.165 Auch das Neue Wiener Tagblatt holte im Jänner 1938 zu einem flammenden Plädoyer für die Erhaltung von „Alt-Wien“ aus: 
„Die Zahl der Demolierung [sic!] von künstlerisch wertvollen, kunsthistorisch bedeutsamen, in jedem Sinn unersetzlichen Baudenkmälern hat in jüngster Zeit bekanntlich in Wien in wahrhaft beklagenswerter Weise unaufhaltsam zugenommen. Das Stadtbild hat dadurch unermeßliche Schädigung erfahren. Dem Fortschreiten dieser höchst sonderbaren und barbarischen Art von ,Straßenregulierung und ,Stadtverschönerung“ soll jetzt unter Zuhilfenahme der maßgebenden zuständigen obersten Faktoren Einhalt geboten werden. Wer Wien liebt, muß zustimmen und der eingeleiteten Aktion beitreten. Das herrliche alte, einmalige Wien soll und muß geschützt und erhalten bleiben, uns und den nachkommenden Geschlechtern."166

Die Aktion sammelte in nur wenigen Wochen 20.000 Unterschriften und noch weitere etwa 10.000 Unterschriften wurden in den letzten Tagen eingeholt. Sedlmayr bezeichnete die Protestaktion später rückblickend als „Protest der Dreißigtausend“, der in der Geschichte der Denkmalschutzbewegung einzigartig sei und „die Verwurzelung des Denkmalschutzgedankens in den Bedürfnissen eines von der Großstadt nicht zerstörten Volkes mit elementarer Wucht erwiesen habe“.167 An anderer Stelle umschreibt er die Protestbewegung als einen „aus der Wurzel einer tiefen Heimatliebe hervorbrechende[n] Selbsterhaltungstrieb der Stadt“.'168 Die Reichspost bewertete die Aktion als lang ersehnten Aufschrei der Wiener Bevölkerung, der beweise, dass „das Bild dieser schönen Stadt und die Erhaltung „Alt-Wiens“ eine Herzenssache von aber Tausenden [sic!] von Wienern“ darstelle und „das echte Wienertum durchaus nicht ausgestorben“ sei. ${ }^{\mathbf{1 6 9}}$ Und auch die Resonanz aus der Politik war groß: Sogar Bundespräsident Wilhelm Miklas sollte über alle weiteren Schritte informiert werden. ${ }^{\mathbf{1 7 0}}$

Die Unterschriftenaktion zeigte jedoch vorerst kaum Auswirkungen. Die beiden Bürgerhäuser in der Singerstraße, die Mitauslöser für die Aktion waren, wurden dennoch abgerissen und auch die von Bürgermeister Schmitz bereits im November 1937 vorgesehene Expertenkommission, die die schwierigeren Anlassfälle diskutieren sollte, ${ }^{\mathbf{1 7 1}}$ war trotz des anhaltenden Protests der Bevölkerung noch nicht eingesetzt worden. ${ }^{\mathbf{1 7 2}}$ Sehr anschaulich wird durch die Aktion die emotionale Stimmung in der Bevölkerung, die - ähnlich wie schon um 1900 - in einer Phase der wirtschaftlichen und politischen Instabilität besonders sensibel auf die fortschreitende Umbautätigkeit reagierte. 
1 Hinsichtlich der Zuschriften vgl. BDA-Archiv, Top. Mat.; zu den Artikeln in der Tagespresse wurde im Bestand historischer Zeitschriften der Österreichischen Nationalbibliothek recherchiert. 2 Auf die Unterschriftenaktion verweist bereits Stefan Plischke, „Wir müssen bauen. Der Assanierungsfonds und die Wohnbaupolitik in Wien 1934-1938“, in: Jan Tabor, Österreich, Bundesministerium für Wissenschaft und Forschung (Hrsg.), Kunst und Diktatur. Architektur, Bildhauerei und Malerei in Österreich, Deutschland, Italien und der Sowjetunion 1922-1956 (Ausstellungskatalog, Künstlerhaus Wien), Baden 1994 S. 216-223, hier S. 222. 3 Eine Abschrift davon findet sich in: BDA-Archiv, Top. Mat., Wien Allg. 2, 1930-1945, div. Denkmäler bzw. Denkmalprojekte, 365/Dsch/1938; ebenso die Unterschriftenliste: ebd., 466/Dsch/1938; und der Aufruf an die Bevölkerung: ebd., 4520/Dsch/1937. 4 Siehe dazu u.a.: Petra Schneider, „Heimweh. Die neue Sehnsucht nach der alten Stadt im Wien um 1900“, in: Karl Brunner, Petra Schneider (Hrsg.), Umwelt Stadt. Geschichte des Natur- und Lebensraumes Wien (Ausstellungskatalog, Wien Museum), Wien/Köln/Weimar 2005, S.584-595. 5 Sándor Békési, „Zwischen Alt und Neu. Umbau und Wahrnehmung von Wien um 1800“, in: Karl Brunner, Petra Schneider (Hrsg.), Umwelt Stadt. Geschich te des Natur- und Lebensraumes Wien (Ausstellungskatalog, Wien Museum), Wien u.a. 2005b, S. 583. 6 Zusendungen und Zeitungsartikel sind in der Topographischen Sammlung des BDA den jeweiligen Adressen zugeordnet. Von den Fachvorträgen ist vor allem jener von Karl Holey zu Beginn des Jahres 1938 zum Thema „Lebende alte Stadtschönheit im Herzen der Großstadt" zu erwähnen, der auch in der Presse kommentiert wurde. Siehe dazu: "Wiens schönes Stadtbild“, in: Neues Wiener Abendblatt, 9. 2.1938, S. 2; Karl Oettinger, „Altes und Neues in der Stadtplanung Wiens“, in: Wiener Zeitung, 2.3.1938, S. 7 7 Bspw. die Zeitungen Das Interessante Blatt oder Neues Wiener Tagblatt. 8 Siehe z.B.: „Ein Stück Alt-Wien: Das Freihaus wird niedergerissen", in: Das interessante Blatt, 6. 2.1936, S. 10. Zahlreiche Artikel zu den einzelnen Objekten finden sich in den Zeitschriften Österreichische Kunst und Österreichische Bauzeitung, vgl. etwa: „Wiener Assanierungsbauten“, in: Österreichische Kunst, 8. Jg., H. 5, 1937, S. 14-15; „Neubauten fertiggestellt“, in: Österreichische Kunst, 8. Jg., H. 12, 1937, S. 21-22. 9 „Ein Neubau auf den Freihausgründen“, in: Österreichische Kunst, 8. Jg., H. 4, 1937, S. 26. 10 Magistrat der Stadt Wien (Hrsg.), Der Wiener Assanierungsfonds. Ein Überblick über die vom Bürgermeister Richard Schmitz eingeführte und durch Beschluß der Wiener Bürgerschaft fortgesetzte Förderung privater Bauvorhaben durch die Stadt Wien in den Jahren 1934-1936 (Wien im Aufbau), Wien 1937b, S. 43-44; „Der Umbau des Freihauses“, in: Österreichische Bauzeitung, 1.Jg., Nr. 4, Jänner 1936, S. 40. 11 „Ein Neubau auf den Freihausgründen Ecke Operngasse“, in: Österreichische Kunst, 8. Jg., H. 3, 1937, S.16. 12 WStLA, 1.5.4. Stadtbaudirektion, A1, Allg. Reg., Schachtel 102/1936, GZ 3202/ 1936, Brief der ZV, des Österreichischen Ingenieur- und Architektenvereins und der Österreichischen Gesellschaft für Städtebau an Bgm. Schmitz, 15.7.1936. 13 Siehe dazu bspw.: „Die Verbauung der Freihausgründe. Die Gesellschaft für Städtebau an den Bürgermeister“, in: Der Wie- ner Tag, 22. 4.1936, S. 5. Die lauteste Kritik äußerte vermutlich Architekt und Baurat Robert Oerley, vgl. dazu: ders., „Die Verbauung der Freihausgründe und das Verkehrsproblem“, in: Österreichische Bauzeitung, 1. Jg., Nr.12, April 1936, S.133-140; ders., „Zur Verbauung der Freihausgründe“, in: Österreichische Bauzeitung, 1.Jg., Nr.15, 20.5.1936, S.173-174. 14 Einer der wichtigsten Bauherren war Oskar Poeller, der mit den Neubauten an der ehemaligen Bärenmühle und Ecke Wienzeile und Faulmanngasse gleich zwei Objekte verwirklichen ließ. Siehe dazu: „Ein Neubau auf den Freihausgründen“, 1937, S. 26. 15 „Ab 1. Mai wird das Freihaus abgebrochen“, in: Neuigkeits-Welt-Blatt, 25.3.1936, S.4. 16 „Die Arbeitsbeschaffung der Gemeinde Wien“, in: Neue Freie Presse, 14. 4.1935, S. 8. 17 „Der Umbau des Freihauses“, Jänner 1936, S. 40. 18 So etwa im Stiegenhaus des „Papagenohofes“ (Operngasse 28); siehe dazu: „Ein Wohnbau und ein Landhaus der Arch. Alfred Adler u. Martin Schmid“, in: Österreichische Kunst, 9. Jg., H. 2, 1938, S.12. 19 Siehe dazu bspw.: BDA-Archiv, Top. Mat., Schleifmühlgasse 12-14, 1656/Dsch/1934, Av von Emmerich Siegris, 3.11.1934. 20 BDA-Archiv, Top. Mat., Wien IV. Bezirk, Profan, Rechte Wienzeile 1, 233/Dsch/1936, Abschrift des Antwortschreibens an die Stadt Wien von Emmerich Siegris, 25.1.1936. In Abstimmung mit den Wiener Städtischen Sammlungen erreichte die Zentralstelle letztlich, die wertvollen Reliefs und die Gedenktafel zu retten (siehe dazu folgende Akten: ebd., 1128/Dsch/1937 und 1577/Dsch/1937). 21 WStLA, Filmarchiv der media wien, Sign. 048, Das Freihaus in Wien, 1936. 22 Siehe dazu das Zeitfenster Min.12:5313:23. 23 „Reichsbahndirektionsgebäude für 1500 Personen. Die Bestimmung der restlichen Freihausgründe", in: Neues Wiener Tagblatt (Mittagsausgabe), 13.10.1938, S. 3. 24 Johannes Sowa, 80 Jahre Wiener Höhenstraße (Archivbilder), Erfurt 2014, S. 101-103. 25 „Verschacherung des Kahlenberges? Ist es der Gemeinde Wien ernst mit der Wiederbelebung des Kahlenberges - Ein Konkurrenzmanöver?", in: Deutschösterreichische Tages-Zeitung, 25.10.1932, S. 5.26 „Wettbewerb zur Aufschließung des Kahlenberges“, in: Profil, 1. Jg., H. 4, 1933, S. X-XII; siehe auch: „Wettbewerb Kahlenberg“, in: Profil, 1. Jg., H. 7, 1933, S. 241-244. 27 „148 Entwürfe und eine tote Idee: Die Kahlenberg-Erneuerung auf 1934 verschoben - Die politischen und wirtschaftlichen Verhältnisse sind schuld", in: Der Wiener Tag, 18.7.1933, S.5; siehe dazu auch: BDAArchiv, Top. Mat., Wien XIX. Bezirk, Profan 2, ehem. Villa Braun-Stammfest, 5209/Dsch/1932. 28 Fertigstellen konnte man das erste Teilstück vom Cobenzl bis zum Kahlenberg, das „Glanzstück der großen Hochstraße durch den Wienerwald“, am 16.10.1935. „Die Wiener HöhenstraBe", in: Amtsblatt der Stadt Wien, 44. Jg., Nr. 19, 1. 10.1936, S.1. 29 Das neue Kahlenbergrestaurant sollte ein wahres "Schmuckstück der Wienerstadt" werden und den wirtschaftlichen und gesellschaftlichen Aufschwung verdeutlichen. Siehe dazu: „Gleichenfeier auf dem Kahlenberg“, in: Amtsblatt der Stadt Wien, 44. Jg., Nr. 11, 1.6.1936, S. 20. 30 BDA-Archiv, Top. Mat., Wien XIX.Bezirk, Profan 2, ehem. Villa Braun-Stammfest, 873/Dsch/1933, Schreiben Sektionschef Leodegar Petrin an die Kahlenberg AG, o.D. 31 Erich Boltenstern, „Der Umbau des Kahlenberghotels“, in: Die Pause, 1.Jg., H.5, 1935, S. 35.32 BDA-Archiv, 
Top. Mat., Wien XIX. Bezirk, Profan 2, ehem. Villa BraunStammfest, 1968/Dsch/1934, Av Emmerich Siegris, 24.12.1934. 33 Ebd., 1574/Dsch/1935, Abtragungsbewilligung, 25.3.1935. 34 Ebd., 1363/Dsch/1935, Av Karl Holey (?), 23.4.1935. 35 „Daher wurden bedeutende Opfer gebracht, um diesen Straßenzug [Billrothstraße-Grinzinger Allee-CobenzIstraße, Anm.d.Autorin] den neuen Verkehrsbedürfnissen entsprechend auszugestalten und die Verkehrssicherheit zu gewährleisten.“ Siehe: „Neugestaltung der Billrothstraße“, in: Amtsblatt der Stadt Wien, 44. Jg., Nr. 12, 15.6.1936, S. 23. 36 Siehe dazu die Bildunterschrift zu einer Abbildung des Palais Paar in: Das Interessante Blatt, 20.1.1938, S.8. 37 K. K. Zentral-Kommission für Kunst- und Historische Denkmale (Hrsg.): Österreichische Kunsttopographie, Bd. 15, Kunsthistorischer Atlas der k. k. Reichshaupt- und Residenzstadt Wien und Verzeichnis der erhaltenswerten historischen, Kunstund Naturdenkmale des Wiener Stadtbildes, Wien 1916, S. 87. 38 BDA-Archiv, Top. Mat., Wien I. Bezirk, Profan, Wollzeile 30, 3194/Dsch/1933, Abschrift des Bescheides, 26.6.1924. 39 Ebd., 314/Dsch/1936, Av Otto Demus, 19.2.1937. 40 Ebd. 41 BDA-Archiv, Top. Mat., Wien I. Bezirk, Profan, Wollzeile 30, 2102/Dsch/1937, Sitzungsprotokoll des Fachbeirates, 15.7.1937. 42 „Die Straßen- und Hofschauseiten des Hauses Wollzeile 30 [...] sind einschließlich des für die künstlerische Gesamtwirkung des Baues höchst bedeutsamen Daches sowie der Architektur der Toreinfahrt unverändert zu erhalten." Vgl. dazu: BDA-Archiv, Top. Mat., Wien I. Bezirk, Profan, Wollzeile 32, 3491/Dsch/1937, Korrespondenz zwischen der MA 31a und der Zentralstelle. 43 BDA-Archiv, Top. Mat., Wien I. Bezirk, Profan, Wollzeile 30, 3628/Dsch/1937, Schreiben der Zentralstelle an die MA 31a, 28.10.1937. 44 In den Akten des BDA ist eine kurze Mitteilung an Sektionschef Leodegar Petrin enthalten: „Die Zentralstelle für Denkmalschutz ist anzuweisen, den Einspruch gegen Abtragung der Häuser Wollzeile 30-32 zurückzuziehen. "Siehe dazu: BDA-Archiv, Top. Mat., Wien I. Bezirk, Profan, Wollzeile 32, 3942/Dsch/1937. 45 Der Unmut der Referenten der Zentralstelle über diese Entscheidung kommt in einigen internen Aktennotizen allerdings deutlich zum Ausdruck: „Schrecklicher Vandalismus!“ (Ginhart) und „Die Demolierung gerade dieser Häuser, deren hoher Kunstwert eine besondere Zierde von Wien war, ist für unsere Stadt ein unersetzlicher Verlust“" (Siegris). Siehe dazu: ebd., 4064/ Dsch/1937, Aktenvermerke vom November 1937. 46 Vgl. dazu die Akten: ebd., 4357/Dsch/1937; 96/Dsch/1938; 147/Dsch/1938. 47 Laut Inge Podbrecky war bereits in den späten 1920er-Jahren zwischen Denkmalpflege und Stadtverwaltung eine Einigung über den Abriss des Dominikanerklosters getroffen worden: dies., Unsichtbare Architektur. Bauen im Austrofaschismus. Wien 1933/ 1934-1938, Innsbruck/Wien 2020, S. 222. 48 BDA-Archiv, Top. Mat., Wien I. Bezirk, Profan, Dominikanerbastei, 3312/ Dsch/1936; 3399/Dsch/1936. 49 Ebd., 3312/Dsch/1936, Vermerk Antwortschreiben Karl Ginhart an die MA 31a, 4.11.1936. 50 Bauverhandlungsprotokolle und Aktenvermerke in: ebd., 3499/ Dsch/1936; 3567/Dsch/1936; 3641/ Dsch/1936; 46/Dsch/1937. 51 Siehe dazu den Schriftverkehr zwischen Dominikanerorden und Zentralstelle in den Akten: ebd., 558/Dsch/1937; 682/Dsch/1937; 792/Dsch/
1937. 52 Ebd., 558/Dsch/1937, Schreiben des Priors an Sektionschef Leodegar Petrin, 12. 2.1937, und am 13.2.1937 verfasstes Antwortschreiben. 53 Ebd., 682/Dsch/1937, Schreiben von Leodegar Petrin, März 1937. 54 Ebd., 792/ Dsch/1937, Schreiben von Leodegar Petrin, 22.2.1937. 55 Wie bereits unter Kap. 5.1.3. erwähnt, zählten neben Petrin, Siegris und Seiberl auch Clemens Holzmeister, Karl Holey und Karl Kraus zu den Mitgliedern des Fachbeirates. 56 Siehe dazu die Aufzeichnungen und den Briefverkehr in den Akten: BDA-Archiv, Top. Mat., Wien I. Bezirk, Profan, Dominikanerbastei, 1030/Dsch/1937; 1155/Dsch/ 1937. 57 Ebd., 1030/Dsch/1937, Beschluss des Fachbeirates in der Sitzung zum Umbau des Dominikanerklosters, 16.3.1937. 58 Ebd., 1356/Dsch/1937, Protokoll der Sitzung bei Vzbm. Lahr mit Vertretern der Stadtverwaltung und der Zentralstelle für Denkmalschutz, 10. 4.1937. 59 Siehe dazu: ebd., 2509/Dsch/1937, Av Herbert Seiberl, 14. 7.1937; ebd., 2567/Dsch/1937, Schreiben des Priors an die Zentralstelle, 13.7.1937. 60 Ebd., 2783/Dsch/1937, Schreiben von Stadtbaudirektor Musil an die Zentralstelle, 28.7.1937. 61 Lediglich ein Deckenfresko konnte abgenommen und erhalten werden. Siehe dazu: ebd., 2783/Dsch/1937, Av (Referent unbekannt), 3.8.1937. 62 Vorrang hatten in der Planung, laut Aussage der Architekten, städtebaulichkünstlerische Aspekte, die zu einer „ehrlichen, endgültigen Lösung des Problems“ führen sollten. Die Platzwand sollte unbedingt erhalten bzw. geschlossen werden, weshalb man sich entschieden gegen einen gänzlichen Durchbruch der Bäckerstraße aussprach, wie er im Generalregulierungsplan ursprünglich vorgesehen war. Siehe dazu: Kurt Klaudy, „Der Dominikaner-Neubau“, in: Österreichische Kunst, 9. Jg., H.10, 1938, S. 27-28. 63 Siehe dazu bspw.: BDA-Archiv, Top. Mat., Wien I. Bezirk, Profan, Dominikanerbastei, 2390/Dsch/1937, anonymes Schreiben an die Zentralstelle zum bevorstehenden Abbruch des Dominikanerklosters, 2. 7.1937; oder BDA-Archiv, Top. Mat., Wien I. Bezirk, Profan, Singerstraße 30-32, 1729/ Dsch/1937, Zuschrift zur geplanten Regulierung der Singerstraße, 7.5.1937. 64 Siehe dazu bspw.: BDA-Archiv, Top. Mat., Wien I. Bezirk, Profan, Singerstraße 30-32, 1729/Dsch/1937, Brief an die Zentralstelle, 7.5.1937. 65 WStLA, 1.5.4. Stadtbaudirektion, A1, Allg. Reg., Schachtel 102/1936, GZ 3202/1936, Schreiben der ZV, der Österreichischen Gesellschaft für Städtebau und des Österreichischen Ingenieur- und Architektenvereins an Bgm. Schmitz, 15.7.1936. 66 Ebd., Schachtel 109/1937, GZ 4353/1937, Brief Clemens Holzmeister an Bgm. Schmitz, 26.10.1937. 67 Ebd., Schachtel 102/1936, GZ 3202/1936, Schreiben der ZV, der Österreichischen Gesellschaft für Städtebau und des Österreichischen Ingenieur- und Architektenvereins an Bgm. Schmitz, 15.7.1936. 68 „Neue Linien im Wiener Stadtbilde“, in: Reichspost, 25.12.1934, S.9-10. 69 Ebd., S.10. 70 Stadtbaurat Musil glaubte allerdings viele Architekten lediglich deshalb als Gegner der Stadtregulierung, da sie bei Assanierungsprojekten nicht zum Zuge gekommen waren, und vermutete bspw. hinter Holzmeisters Unterstützung der Unterschriftenaktion von 1938 die erfolglose Bewerbung um den Umbau des Palais Paar in der Wollzeile. Siehe: WStLA, 1.5.4. Stadtbaudirektion, A1, Allg. Reg., Schachtel 110/1938, GZ 236/1938, Brief Stadtbaudirektor Franz Musil an Bgm. Schmitz, 26.1. 1938. 
$71 \mathrm{Zu}$ Holzmeisters Rolle im Ständestaat siehe v.a.: Wilfried Posch, Clemens Holzmeister. Architekt zwischen Kunst und Politik, Salzburg 2010, vor allem S. 229-259. 72 Clemens Holzmeister, Architekt in der Zeitenwende, 2 Bde., Bd. 1, Selbstbiographie. Werkverzeichnis, Salzburg u. a. 1976, S. 49, zitiert nach: Suttner, S. 102; zur Rolle von Clemens Holzmeister siehe auch: Gertrude Enderle-Burcel, Mandatare im Ständestaat, 1934-1938. Christlich - ständisch - autoritär. Biographisches Handbuch der Mitglieder des Staatsrates, Bundeskulturrates, Bundeswirtschaftsrates und Länderrates sowie des Bundestages, Wien 1991 S. 105. 73 Helmuth Weihsmann, In Wien erbaut. Lexikon der Wiener Architekten des 20. Jahrhunderts, Wien 2005 S. 276-277. 74 Robert Oerley, „Wie ich Wien umbauen würde ... Donaustadt der Zukunft", in: Neues Wiener Tag blatt, 8. 4.1936; Angaben nach: Wienbibliothek im Rathaus, Tagblatt-Archiv, Stadtplanung 1902-1937, AC09396305. 75 BDA-Archiv, Heimatschutz, Karton 10, Tagungen und Kongresse (1934-1941), Fasz. 3 (1936). 76 Der Lehrstuhl wurde im Jahr 1932 von Erwin IIz an der TH gegründet. Erst mit der Einrichtung des Lehrstuhls wurde eine Ausbildung im Bereich des Städtebaus im Rahmen des Architekturstudiums an der TH ermöglicht. Christoph Braumann, Stadtplanung in Österreich von 1918 bis 1945 Unter besonderer Berücksichtigung der Stadt Salzburg (Schriftenreihe des Institutes für Städtebau, Raumplanung und Raumordnung, TU Wien, 21), Wien 1986, S.12. 77 Hugo Hassinger, „Um die Erhaltung und Neugestaltung des Wiener Stadtbildes“, in: Reichspost, 20.1.1938, S.7. Hassingers Aussage wird durch die Tatsache unterstrichen, dass Holey und IIz, wie auch Hassinger, Mitglieder des Österreichischen Verbandes für Heimatpflege waren. 78 Ebd. 79 Karl Holey, Architekt und Dombaumeister, war von 1914 bis 1939 als technischer Generalkonservator für die Zentralstelle tätig. Ab 1926 lehrte er als ordentlicher Professor an der TH Wien, wo er sich 1920 in der Geschichte des Städtebaus habilitiert hatte. Theodor Brückler, Ulrike Nimeth, Personenlexikon zur österreichischen Denkmalpflege, Wien 2001, S.113. 80 Die Vorlesungen zur Denkmalkunde und zum Thema „Geschichte des Städtebaus" wurden von Holey in den Studienjahren 1933/34, 1936/37, 1937/38 und 1938/39 gelesen; vgl. dazu die jeweiligen Bände der Publikationsreihe Technische Hochschule Wien, Vorlesungsverzeichnis, Studienpläne und Personalstand, Wien 1907-1937. 81 Brückler/ Nimeth 2001, S.113. 82 Die Schönheit der Städte übe „auf das primitive ästhetische Empfinden des Volkes eine starke Wirkung“ aus und „vielmehr als das einzelne Bauwerk prägt sich die künstlerische Gesamtwirkung eines Stadtbildes auch dem naiv empfindenden Menschen ein“. Siehe dazu: Karl Holey, „Im neuen Rom das alte Rom“, in: Mitteilungen des Vereins der Freunde des humanistischen Gymnasiums, H. 33, 1936, S. 51-59, hier S. 52. 83 So Karl Holey im Vorwort zum Katalog der Ausstellung, siehe: ders., Ausstellung Italiens Stadtbaukunst (Ausstellungskatalog, Secession Wien), Wien 1937, S. 5. 84 Stadtbau direktor Musil erwähnt „einen objektiv gehaltenen Artikel“ zum Thema, den Holey verfasst habe. Vgl. WStLA, 1.5.4 Stadtbaudirektion, A1, Allg. Reg., Schachtel 110/1938, GZ 236/1938, Brief Stadtbaudirektor Franz Musil an Bgm. Schmitz, 26.1.1938. 85 Karl Holey, „Staatskunst und
Baukunst", in: Reichspost, 12.4.1936, S. 3. 86 Siehe dazu noch genauer Kap. 6.2.3. 87 Holey, 12.4.1936, S. 3. 88 Holey 1936, S.57-59. 89 Siehe dazu den ausführlichen Bericht über Holeys Vortrag in der Tagespresse: „Wiens schönes Stadtbild“, 9.2.1938, S. 2. 90 Ilz hatte die Professur für Städtebau an der TH bis ins Jahr 1945 inne. Seinen Einfluss auf die städtebaulichen Planungen des NS-Regimes in Wien ab 1938 beleuchten Siegfried Mattl, Gottfried Pirhofer, „Wien. ,Tor zum Südosten'. Stadt- und Regionalplanung im Kontext imperialer Raumpolitik“, in: Ingrid Holzschuh, Monika Platzer, Architekturzentrum Wien (Hrsg.), „Wien. Die Perle des Reiches“. Planen für Hitler (Ausstellungskatalog, Architekturzentrum Wien), Zürich 2015, S. 12-25. 91 Technische Hochschule Wien, 19071937. 92 BDA-Archiv, Top. Mat., Wien Allg. 2, 1930-1945, div. Denkmäler bzw. Denkmalprojekte, 290/Dsch/1938, Brief Karl Giannoni an Zentralstelle und Memorandum, 26.1.1938. 93 Erwin IIz, „Neue Aufgaben des Städtebaues“, in: Ingenieurkammer für Wien, Niederösterreich und Burgenland (Hrsg.), Festschrift anläßlich des 75jährigen Bestandes der Ziviltechniker. 75 Jahre Ziviltechniker, Wien 1935a, Sonderabdruck, S.1-6, hier S. 4. 94 Erwin IIz, „Stadtbaukunst und Verkehr“, in: Zeitschrift des Österr. Ingenieur- und Architektenvereines, H. 51/52, 1935b, S. 307-310, hier S. 309. Als Beispiel nennt IIz in einer seiner Publikationen den Kölner Dom und seine Umgebung. Die einstige Verbauung des Kölner Doms trug „in ihrer malerischen Gesamtwirkung den stadtbaukünstlerischen Raumforderungen gebührend Rechnung“, ihre Schleifung und die Freilegungspraxis des 19. Jhs. und die nicht auf lange Sicht geplanten verkehrsbedingten Eingriffe (Bsp. Bahnlinienführung) hätten dieses Zusammenspiel zerstört. 95 Ebd., S. 307, 309. 96 OEStA, AdR BKA BKA-I BPDion Wien VB Sig.XVIII 8742, Mitteilungen über die Wahlen des Ausschusses an die Polizeidirektion Wien, 1928 und 1934. 97 Dies erkenne man an den Plänen für den Ballhausplatz und das Fronthaus. Erwin IIz, „Gegenwartsaufgaben des Städtebaues, mit besonderer Berücksichtigung Österreichs, Deutschlands und Italiens", in: Zeitschrift des Österr. Ingenieur- und Architektenvereines, Sonderabdruck, H. 1/2 und 3/4, 1938, S. 1-9, hier S. 5-6. 98 Erwin IIz, „Rettung für Alt-Wien. Neue Wege und Möglichkeiten“, in: Neues Wiener Journal, 6.1.1938, S.6. 99 Sedlmayr lehrte auch an der TH Wien als Privatdozent und las dort Mitte der 1930er-Jahre zur "Geschichte der künstlerischen Stadtgestaltung": BDA-Archiv, Karton 3, Teilnachlass Hans Sedlmayr, Liste der Vorlesungen HS, 2.3. Nachlass Sedlmayr - Biographisches, Vortragsliste 1931-1983; und zu „Geschichte und Aufgaben der Stadtbaukunst in Österreich": Technische Hochschule Wien, 1907-1937, S. 77. 100 BDA-Archiv, Karton 3, Teilnachlass Hans Sedlmayr, Autobiographische Aufzeichnungen, 2.1.3. H.Sedlmayr, „Tätigkeit und Veröffentlichungen für den Denkmalschutz“, o. D. 101 Hans Sedlmayr, „Die Gefahr für Alt-Wien“, in: Neues Wiener Tagblatt, 6.3.1938, S. 9; ders., "Stadtgestaltung und Denkmalschutz", in: Deutsche Kunst und Denkmalpflege, 1939/40, S.151-161, hier S. 156. 102 Stadtbaudirektor Musil hatte seinen Lehrstuhl als Ausgangspunkt der Unterschriftenaktion verdächtigt, da er seiner Ansicht nach „in enger Fühlungnahme mit den Kreisen der Zentralstelle für Denkmalschutz" stehe. Siehe 
dazu: WStLA, 1.5.4. Stadtbaudirektion, A1, Allg. Reg., Schachtel 110/1938, GZ 236/1938, Brief Stadtbaudirektor Franz Musil an Bgm. Schmitz, 26.1.1938. 103 Sedlmayr, 6.3.1938, S. 9. 104 Sedlmayr 1939/40, S. 159; zu seinen Überlegungen zum „konkreten Städtebau“ siehe v.a.: S.151-152. 105 Zu den konkreten Plänen für Wien siehe u. a.: Ingrid Holzschuh, Wiener Stadtplanung im Nationalsozialismus von 1938 bis 1942. Das Neugestaltungsprojekt von Architekt Hanns Dustmann, Köln 2011; sowie dies., „Verlorene Stadtgeschichten. Hitlers Blick auf Wien“, in: dies., Monika Platzer, Architekturzentrum Wien (Hrsg.), „Wien. Die Perle des Reiches“. Planen für Hitler (Ausstellungskatalog, Architekturzentrum Wien), Zürich 2015, S. 28-45. 106 BDA-Archiv, Karton 3, Teilnachlass Hans Sedlmayr, 2.6.4. Korrespondenz mit Karl Oettinger, Brief, Herbst 1940. 107 Oettinger, 2.3.1938, S.7. 108 Petra Svatek, „Raumforschung an der Universität Wien im 20. Jahrhundert. Kontinuitäten und Wandlungen einer multidisziplinären und politisch orientierten Forschungsrichtung“, in: Katharina Kniefacz u.a., Universität - Forschung-Lehre. Themen und Perspektiven im langen 20. Jahrhundert (650 Jahre Universität Wien - Aufbruch ins neue Jahrhundert, 1), Wien 2015, S. 241-259. 109 Hassinger, 20.1.1938, S. 7. $110 \mathrm{Im}$ Jahr 1934 war in der Bezeichnung des Vereins das Wort „Heimatschutz“ mit dem Begriff „Heimatpflege“ ausgetauscht worden, „um Verwechslungen mit der politischen Heimatschutzorganisation vorzubeugen“. Dies berichtet Karl Giannoni selbst: OEStA, AdR BKA BKA-I BPDion Wien VB Sig. XVIII 8742, Mitteilung über die Wahlen des Ausschusses an die Polizeidirektion Wien, 2.5.1934. 111 Etwa an der 13. Österreichischen Bundestagung für Heimatpflege im Jahr 1934; siehe dazu den ausführlichen Tagungsbericht: BDA-Archiv, Heimatschutz, Karton 1a, Verwaltungsakten 1923-1940, 1190/Dsch/1934. 112 Hans Tietze, Flugschriften des Vereines zum Schutze und zur Erhaltung der Kunstdenkmäler Wiens und Niederösterreichs, 6 Bde., Bd. 4, Das Wiener Stadtbild, Wien 1910, S. 43. 113 Max Dvořák, Flugschriften des Vereines zum Schutze und zur Erhaltung der Kunstdenkmäler Wiens und Niederösterreichs, 6 Bde., Bd. 2, Zur Rettung Alt-Wiens, Wien/Leipzig 1910, S.86. 114 Karl Giannoni war, wie bereits in Kap. 1 erwähnt, wohl der entscheidendste Vertreter der österreichischen Heimatschutzbewegung von deren Beginn bis in die Zeit des Nationalsozialismus. 1908 trat er in den Dienst der Zentralkommission, spätere Zentralstelle bzw. (Bundes-)Denkmalamt, ein, 1913 (ein Jahr nach der Gründung des Österreichischen Heimatschutzverbandes) wurde er zum „staatlichen Konsulenten für Heimatschutz" ernannt. Siehe dazu: Brückler/Nimeth 2001, S. 82. 115 Wilfried Kirsch, „Vom Werden des Österreichischen Heimat- und Naturschutzes", in: Deutsche Kunst und Denkmalpflege, 5. Jg., S. 62-64, hier S. 63; siehe dazu auch: Eva Frodl-Kraft, Gefährdetes Erbe. Österreichs Denkmalschutz und Denkmalpflege 1918-1945 im Prisma der Zeitgeschichte (Studien zu Denkmalschutz und Denkmalpflege, 16), Wien u.a. 1997, S.78; sowie BDA-Archiv, Heimatschutz, Karton 3a, Vereinskorrespondenz, Fasz. 3 (1922-1940). 116 OEStA, AdR BKA BKA-I BPDion Wien VB Sig. XVIII 8742, Mitteilungen über die Wahlen des Ausschusses an die Polizeidirektion Wien, 1928 und 1934. 117 Zu den diversen Ausstellungen siehe: BDA-Archiv, Heimatschutz, Karton 5, Ausstellungen 1920-1940. Die Ausstellungen fanden vor allem im östlichen Teil Österreichs statt, in Niederösterreich, Wien, Oberösterreich, Burgenland und der Steiermark (Graz). 118 Ebd., Fasz. 1, 2046/Dsch/1938, Schreiben Karl Giannoni an die Zentralstelle, 1.7.1938. In einem Schreiben an den Bund des schwedischen Heimatschutzes berichtet Giannoni davon, dass die Organisation auch im „(Alt-) Reich und in der Schweiz als mustergültig anerkannt" werde. Siehe: BDA-Archiv, Heimatschutz, Karton 3a, Vereinskorrespondenz, Fasz. 3 (1922-1940), Brief, 21. 4.1938. 119 BDA-Archiv, Heimatschutz, Karton 3a, Vereinskorrespondenz, Fasz. 3 (1922-1940), Brief, 21.4.1938. 120 Karl Giannoni, Flugschriften des Vereines zum Schutze und zur Erhaltung der Kunstdenkmäler Wiens und Niederösterreichs, 6 Bde., Bd. 6, Heimatschutz, Wien/Leipzig 1911b, S. 6. 121 „Bauliche Heimatpflege“, in: Österreichische Bauzeitung, 1. Jg., Nr. 15, 20. 5.1936, S. 175-176, hier S. 176. 122 Karl Giannoni, Grundfragen des Heimatschutzes, Wien 1933b, S. 10; vgl. dazu auch Wolfgang Sonne, „Stadterhaltung und Stadtgestaltung. Schönheit als Aufgabe der städtebaulichen Denkmalpflege“, in: Hans-Rudolf Meier (Hrsg.), Werte. Begründungen der Denkmalpflege in Geschichte und Gegenwart, Berlin 2013, S. 158-179, hier S.170. 123 Giannoni 1933b, S. 10124 Theodor Brückler, „Zur Geschichte der Österreichischen Heimatschutzbewegung“, in: ÖZKD, 43. Jg., H. 3/4, S. 145-156, hier S. 147, 154. 125 Ab 1934 lief die Ausstellung unter dem Titel Fremdenverkehr und Schutz der Heimat (bspw. 1934 in Klosterneuburg) und unter Heimatpflege und Fremdenverkehr (bspw. 1936 in Mauer bei Wien). 1938 lief sie in Graz unter dem Titel Das Kunsterbe in Österreich; siehe dazu: BDAArchiv, Heimatschutz, Karton 5, Ausstellungen 1920-1940, Fasz. 7 und 8. 126 Ebd., Fasz. 5, 1935, Brief Giannoni an den Bezirksschulrat Freistadt, 25.9.1935. 127 So der Leitgedanke der Ausstellung, zu lesen auf einer Schrifttafel zur Ausstellung, Fotografie im BDA-Fotoarchiv, Ordner Heimatschutz I, A-Gel. 128 Dieses und die in diesem Absatz folgenden Teilzitate sind den Ausstellungstafeln entnommen. Fotografien und z. T. Originale der Ausstellungstafeln sind im Fotoarchiv des BDA zu finden (Heimatschutz, diverse Ordner, alphabetisch nach den Themen der Ausstellung sortiert). 129 So die Bildunterschrift zum Looshaus auf einem Plakat zu „guten“ und „schlechten“ Bürgerhäusern. 130 BDA-Archiv, Heimatschutz, Karton 6a, Div. Mat. (Fasz. 1-10), Fasz. 9 (Stadtbild Wien), Schreiben Hugo Hassinger, 25.11.1937. 131 Zu den zeichnenden Vereinigungen zählten neben dem Österreichischen Verband für Heimatpflege u. a. der Albrecht Dürer-Verein, die Deutsche Kunstgemeinschaft, die Secession und die ZV. Vgl. dazu: BDA-Archiv, Heimatschutz, Karton 6a, Div. Mat. (Fasz. 1-10), Fasz. 9 (Stadtbild Wien), Abschrift des Briefes an den Bgm. von Wien samt Memorandum, 15.1.1938, S. 4. 132 BDA-Archiv, Top. Mat., Wien Allg. 2, 1930-1945, div. Denkmäler bzw. Denkmalprojekte, 290/Dsch/1938, Brief Karl Giannoni an die Zentralstelle und Memorandum, 26.1.1938. 133 Dies lässt sich anhand der im BDA-Archiv erhaltenen Korrespondenz rekonstruieren. Siehe dazu: BDA-Archiv, Heimatschutz, Karton 6a, Div. Mat. (Fasz. 1-10), Fasz. 9 (Stadtbild Wien), Briefe von Hans Sedlmayr und Robert Oerley, 11. und 14.1.1938. 134 Dieses und die 
folgenden Zitate und Inhalte entstammen dem Memorandum: BDA-Archiv, Top. Mat., Wien Allg. 2, 1930-1945, div. Denkmäler bzw. Denkmalprojekte, 290/Dsch/1938, Memorandum. 135 Gemäß Memorandum sollten erhaltenswerte Gebäude in einem Plan erkenntlich gemacht und die Fluchtlinien des Flächenwidmungs- und Bebauungsplanes der Bewertung der Gebäude angepasst werden. 136 Siehe bspw.: „Das Neue Wien“, in: Allgemeiner Tiroler Anzeiger, 17. 2.1938, S.6; „Wiener Assanierungsbauten“, in: Mühlviertler Nachrichten, 18.2.1938, S.8. 137 „Fort mit den Verkehrshindernissen in Wien. Ein Jahr Arbeit für 40.000 Arbeitslose“, in: Neues Wiener Journal, 20.9.1934, S. 3. 138 „Neue Linien im Wiener Stadtbilde“, 25.12.1934, S. 9. 139 Schuld gab man der neuen Mietgesetzgebung im Jahr 1922, da durch die verringerten Mieteinnahmen die private Bautätigkeit nahezu ausgeschalten worden sei. Siehe dazu: BGBI. 822/1922 über die Miete von Wohnungen und Geschäftsräumlichkeiten (Mietengesetz) und für Wien LGBI. 59/1922 zur Einführung einer allgemeinen Mietzinsabgabe im Gebiete der Stadt Wien. 140 „Neue Linien im Wiener Stadtbilde“, 25.12.1938, S. 9. 141 „An allen Ecken und Enden“, in: Neue Freie Presse, 14.10.1936, S. 3. 142 „Fort mit den Verkehrs hindernissen“, 20.9.1934, S.3. 143 „Arbeitsbeschaffung durch Altstadtsanierung", in: Der österreichische Baumeis ter, 2. Jg., H. 5, 10. 2.1935, S. 86. 144 „Die Straße frei der neuen Zeit“, in: Die Pause, 2. Jg., H. 6, 1937, S. 44-47. Die Berichterstattung erfolgte vor allem auch über die Zeitschrift Österreichische Kunst. 145 „Der neue Wohnbau am Laurenzerberg - von Baurat Zivilarch. Angelo Felix Pollak“, in: Österreichische Kunst, 7. Jg., H. 9, 1936, S. 30. 146 Zur Ausstattung der Wohnungen vgl. etwa „Modernste Einrichtung im Assanierungsbau“, in: Profil, 3. Jg., H. 6 , 1935, S. 304. 147 So konnte etwa die Wirkung der Fassade des Neubaus am Laurenzerberg durch die „Gliederung und grüne Umrahmung der Fenster, durch die Balkongitter und Verglasungen vom kalt nüchternen zum bewegten und freundlichen Eindruck gemildert" werden siehe dazu: „Der neue Wohnbau am Laurenzerberg“, 1936 S. 30. 148 Ebd. 149 „Lasst uns noch ein paar alte Gassen ...!“, in: Wiener Journal, 23.1.1938, S. 9. 150 „Für Erhaltung des alten Wien“, in: Wiener Neueste Nachrichten, 22.1.1938, S. 3. 151 „Aufruf zur Erhaltung von Alt-Wien“, in: Neue Freie Presse, 21.1.1938, S.6. 152 „Fünf edle Häuser bitten um Gnade“, in: Reichspost, 25.4.1937, S.7-8. 153 Siehe dazu bspw.: „20.000 Wiener für die Erhaltung des Alt-Wiener Stadtbildes“, in: Reichspost, 22.1.1938, S. 2. 154 „Rettet Wiens künstlerisches Stadtbild“, in: Österreichische Kunst, 9. Jg., H. 2, 1938, o.S. 155 "Ist Alt-Grinzing bereits verloren?", in: Neuigkeits-WeltBlatt, 14.8.1937, S. 4. 156 Brückler/Nimeth 2001, S. 243. 157 BDA-Archiv, Top. Mat., Wien Allg. 2, 1930-1945, div. Denkmäler bzw. Denkmalprojekte, 365/Dsch/1938, Av Karl Ginhart, 5. 2.1938. Schneider sandte nicht nur Briefe an die Zentralstelle, sondern auch an Bgm. Schmitz und Kardinal Theodor Innitzer. 158 „Bitten will ich Sie, Herr Bürgermeister, schützen Sie unsere Stadt vor den Gelüsten der Bauspekulanten, die Arbeitsbeschaffung sagen und ihren Geldbeutel meinen. Der Assanierungsfonds darf nicht von skrupellosen Baufirmen mißbraucht werden [...]. Es darf nicht so weit kommen, daß der Volkswitz sich seiner bemächtigt und inn zum ,Demolierungsfonds' macht." Siehe: ebd., 1730/Dsch/1937, Brief Viktor Schneider an Bgm. Schmitz, 28.4.1937, S. 3. 159 BDA-Archiv, Top. Mat., Wien Allg. 2, 1930-1945, div. Denkmäler bzw. Denkmalprojekte, 1730/Dsch/1937, Brief Viktor Schneider an Bgm. Schmitz, 28. 4.1937, S. 1. 160 Zitat aus dem Brief eines Baurats aus Stuttgart an Bgm. Schmitz vom Jänner 1938: „Wie beglückend persönlich sind oft auch die bescheidenen Bürgerbauten des alten Wien! [...] die vielen Köstlichkeiten machen mehr Wiens Charakter aus, den wir alle so lieben - wir Fremde vielleicht noch mehr als die Wiener selbst - als die grossen [sic!] Straßenfluchten mit 6 Stockwerken und mehr, als vielleicht selbst die schöne Lage Wiens mit seinem Wienerwald." Vgl. WStLA, 1.5.4. Stadtbaudirektion, A1, Allg. Reg., Schachtel 110/1938, GZ 356/1938, Brief eines Baurats aus Stuttgart an Bgm. Schmitz, 26.1.1938. 161 BDA-Archiv, Top. Mat., Wien IX. Bezirk, Profan, Lichtentalergasse, 4042/Dsch/1932, Privater Brief an das BDA, 3.9.1932. 162 Gezeichnet wird die Denkschrift von Konstantin Dumba (ehem. Diplomat und Präsident der österreichischen Völkerbundliga), Hans Finsterer (Universitätsprofessor), Oskar von Heimerich (Feldmarschallleutnant a. D.), Gräfin Margarete Lanckorońska, Johannes Prinz von und zu Liechtenstein, Dr. Max Mell, Dr. Franz Schmidt und Karl Graf von Wilczek, vgl. BDA-Archiv, Top. Mat., Wien Allg. 2, 1930-1945, 365/Dsch/1938. Die alphabetisch geordnete Unterschriftenliste ist zu finden in: ebd., div. Denkmäler bzw. Denkmalprojekte, 466/Dsch/1938; wie auch der vorausgegangene Aufruf an die Bevölkerung: ebd., 4520/Dsch/1937. 163 Siehe dazu den kritischen Zeitungsartikel von Karl Oettinger, „Die Zerstörung der Singerstraße überflüssig“, in: Neues Wiener Tagblatt, 30.1.1938, S. 8. 164 BDA-Archiv, Top. Mat., Wien Allg. 2, 1930-1945, div. Denkmäler bzw. Denkmalprojekte, 365/Dsch/1938, Denkschrift zur Erhaltung des Alten Wien. 165 „Rettet Wiens künstlerisches Stadtbild“, 1938, o. S. 166 „Das bedrohte alte Wien“, in: Neues Wiener Tagblatt, 22.1.1938, S. 5. 167 Sedlmayr 1939/40, S. 158. 168 Sedlmayr, 6.3.1938, S. 9.169 „20.000 Wiener für die Erhaltung des Alt-Wiener Stadtbildes“, 22.1.1938, S. 2. 170 In einem Schreiben an das Bundesministerium für Unterricht ersuchte die Präsidentschaftskanzlei, „angesichts des großen Interesses, das der Herr Bundespräsident für die in Rede stehende Angelegenheit bekundet", um Mitteilung über etwaige Verfügungen und Entscheidungen. Vgl. dazu: BDA-Archiv, Top. Mat., Wien Allg. 2, 1930-1945, div. Denkmäler bzw. Denkmalprojekte, GZ 466/Dsch/1938, Schreiben an das Bundesministerium für Unterricht, 5. 2.1938. 171 WStLA, 1.5.4. Stadtbaudirektion, A1, Allg. Reg., Schachtel 109/ 1937, GZ 4587/1937, Schreiben Stadtbaudirektor Franz Musil an den Magistratsdirektor, 29.11.1937. 172 Ebd., Schachtel 110/1938, GZ 236/1938, Brief Stadtbaudirektor Franz Musil an Bgm. Schmitz, 26.1.1938. 

Kapitel 6 